\title{
A SURVEY OF SWITCH-REFERENCE IN NORTH AMERICA
}

\author{
Andrew McKenZIE
}

UNIVERSITY OF KANSAS

\begin{abstract}
This paper introduces a new survey of switch-reference in the languages of North America. The survey's purposes are to provide a broad basis for future analysis of switchreference (SR), spur further research on the languages included, and help revitalization efforts with a better understanding of what SR looks like and how it works.

The survey catalogs 33 facts about SR morphology, semantics, and syntax, organized around central questions in SR research. The paper discusses the major findings based on the survey, some of which have major implications for theories of switch-reference: SR is found in nearly 70 American language varieties, mostly in the western United States and Mexico, often spreading by areal diffusion. Cross-linguistically, SR usually indicates subject co-reference across clauses. It is associated with every type of clause juncture except disjunction and is found throughout the verbal morphology. Morphological homophony with case is not due to a common semantic core.
\end{abstract}

[KEYWORDS: switch-reference, typology, morphology, syntax, clause-chaining]

1. Introduction and motivations. This paper presents a survey of switch-reference in the indigenous languages of North America. ${ }^{1}$ The intent of the survey is to collect what is known about this phenomenon in these languages, to serve several purposes. One is to form a solid empirical basis for typological generalizations and theoretical proposals. Another is to highlight gaps in our knowledge that can be filled by further research. A third is to lead toward a more complete understanding of switch-reference that can benefit communities striving to maintain or revitalize their language.

The complete survey can be found in the electronic appendix to this paper, which appears in the online version only. The discussion in this paper is divided into a series of broad questions whose answers are revealed by the survey.

1.1. Introduction to switch-reference. Switch-reference (SR) can be defined as a set of morphemes associated with the juncture of two clauses that indicates whether a certain prominent argument in each clause co-refers.

1 Thanks go to audiences at a number of conferences, workshops, and reading groups, including SSILA's annual meeting, where an earlier version of this paper was presented. Notable thanks to those who have pointed out new languages and areas to search. Parts of this work were supported by the University of Kansas College of Liberal Arts and Sciences. I would also like to thank the IJAL reviewers and associate editors who helped me craft this article into a presentable form.

[IJAL, vol. 81, no. 3, July 2015, pp. 409-48]

(C) 2015 by The University of Chicago. All rights reserved.

0020-7071/2015/8103-0004\$10.00 
Typically, that argument is the subject. If the clauses' subjects co-refer, SR appears in a value known as SS or "same-subject" marking. If they are disjoint, SR appears as DS or "different-subject" marking. Sometimes, however, SR ignores subjects in favor of events or situations.

Example (1) from the Kiowa language exemplifies switch-reference well. The two sentences are identical except for the SR morpheme. In (1a), subjects co-refer and SS marking appears - the person who came in is the person who sat down. In (1b), DS marking appears, and the sentence is only felicitous if someone else sat down instead.

(1) Switch-reference with subordination in Kiowa (McKenzie 2012:46)

(1a) $\emptyset$-hé:ba=tsẽ: $\quad$ em-só:

$3 \mathrm{~s}-$-enter:PF=when:SS 3sA:RO-sit.down:PF

'[When she ${ }_{1}$ came in], she s/*2 $_{2}$ sat down'. ${ }^{2}$

(1b) $\emptyset$-hé:ba=ẽ:

em-só:

3s-enter:PF=when:DS 3sA:RO-sit.down:PF

'[When she $_{1}$ came in], she $*_{* 1 / 2}$ sat down'.

In many languages, however, SR is sometimes observed to ignore subjects altogether. In (2), from Lakota, the subjects change between clauses 2 and 3, but SS marking still connects them.
$\check{c}^{\mathrm{a}} \tilde{\mathrm{a}}$ ota ileya-pi wood much
make.burn-PL
na and:SS
el ixpeya-pi on place-pl
na
hečhel xuynaye thus burn up
'they set fire to a lot of wood and they placed him on it and he burned up ( "was in a burned-up state")'
(Dahlstrom 1982:73)

2 The data in the paper are presented in the orthography used in the sources. In the survey, the data are written in the IPA. The glosses mostly follow the Leipzig Glossing Rules. One exception is that portmanteaus are glossed linked by a colon rather than a period. Another exception is the following list of abbreviations: ABS absolute clause, ADL adlative case, CIS cislocative, DIM diminutive, DCT direct, DIR directional verb, DS different "subject"/DS marking, EMPH emphatic, F aspectual falling grade, FEM feminine, $\mathrm{H}$ aspectual h-grade, I inverse number marking, IMPF imperfective, INDEF indefinite base, INTER interrogative, L aspectual l-grade, LOG logophor, o object, OBV obviative, P/PL plural, PAT patient, PF perfective, PROX proximate, $\mathrm{R}$ reflexive, REF referential/ anaphoric, RLS realis, s singular, SEQ sequential, sIMUL simultaneous, SS same "subject"/SS marking, TNS tense marking, TRL translocative, UT unspecified time.

To maintain an internal consistency, I have changed some of the glosses slightly from their original source. Most changes unify different abbreviations, e.g., for past tense. Also, I adjust marking for morpheme boundaries based on the source's analysis. If a source labels something a "clitic," I mark its boundary here with =, no matter which symbol the source used. More significantly, I occasionally collocate complex morphology into a single clear form when it is not relevant to the discussion of switch-reference. If a glossing change is significant (as with Creek SR markers), the change is discussed and motivated in situ. 
This "non-canonical SR" is discussed in more detail in $\mathbf{4 . 1}$ below. Despite ignoring subjects, non-canonical SR is still "tracking" the reference of some prominent argument in each clause. Therefore, when discussing SR in general, we need terminology to describe what it tracks. I adopt the terminology in McKenzie (2012): The pivot is the argument that SR tracks in its own clause, and the anti-pivot is the argument that it tracks in the joined clause. The two clauses themselves are called the pivot clause and the anti-pivot clause, respectively. The characterization of SR targets as pivots allows for a clean definition of non-canonical SR: It occurs when the pivot and anti-pivot are not the subjects of their clauses. These terms are used especially in discussions of structure ( 5 below), where the asymmetry between pivot clauses and antipivot clauses is important. These terms allow for a discussion of asymmetry, without making assumptions about the clause structures, and draw a direct link between the targets of SR and the clauses they are in. ${ }^{3}$

Many languages have multiple sets of SR morphemes. Each set's occurrence is linked in some way to that of a particular sentential connective. In Kiowa, tsẽe:/ẽ: occurs as part of a connective translated as 'when'. SR in Kiowa also occurs on coordinating conjunctions gJ/ñ (Watkins 1993). The distribution of SS and DS in (3) is identical to that in (1).

(3) Switch-reference with coordination in Kiowa (McKenzie 2012:82)

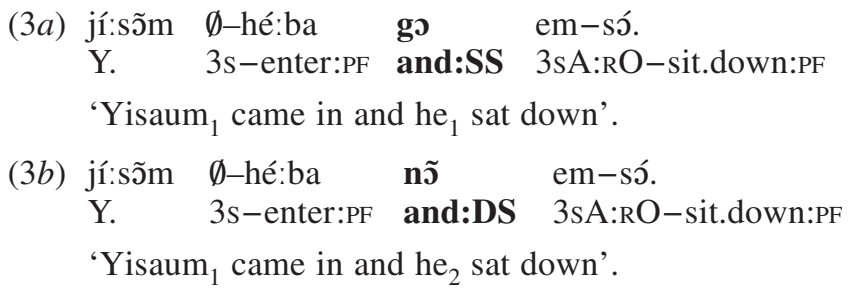

1.2. Motivations. Switch-reference (SR) is a phenomenon that has intrigued linguists for over 50 years, and the study of North American languages has shaped the research on it from its first discoveries by Jacobsen (1967). Jacobsen (1983) provided a survey of SR in North American languages and was able to make some typological generalizations about switch-reference. The present survey is an update of the previous one. In the 30 years since then, SR systems have been described in many more North American languages, as well as in languages all over the world. ${ }^{4}$ As it turns out, this survey is about what we do not know as much as it is about what we do know. The

\footnotetext{
${ }^{3}$ Haiman and Munro (1983) employ the terms "marked clause" for pivot clause and "controlling clause" for anti-pivot clause. These terms were widely used in some parts of the SR literature. However, some confusion is possible, for MARKEDNESS and especially CONTROL have very precise meanings in linguistic theory. On the other hand, PIVOT does not, and ANTI-PIVOT is not used.

${ }^{4}$ Surveys include Austin (1981) for Australian languages and Roberts (1997) for Papua New Guinea languages. McKenzie (2012) briefly lists findings in South America, Africa, and Asia as well. One reviewer suggested Wiesemann's (1982) examination of SR in Bantu languages,
} 
survey reveals many gaps in our understanding of SR in languages, which can be filled with additional research. These lacunae stem largely from the lack of guideposts and milestones to guide research on the phenomenon. One goal of this paper is to contribute to that guidance, by discussing the major questions concerning SR and what the survey reveals to us. With any luck, researchers with an interest in SR or language description will fill those gaps with new discoveries.

In addition, several theoretical accounts have raised and addressed many questions about switch-reference. The phenomenon has received yet more attention in recent years, but the research nearly all focuses on only one or a handful of languages. Thus, it has rarely borne the fruits of a comparative perspective.

Besides aiding linguistic research, the survey is meant to broaden perspectives on switch-reference for language programs in communities interested in maintaining or revitalizing Native languages. Switch-reference is a tricky bit of language, but a crucial one, because it is a frequent feature of fluent speech and traditional narrative. In communities where first-language acquisition is no longer taking place, a conscious command of SR systems is crucial to ongoing language transmission.

The rest of this paper presents the survey in sections devoted to the major issues at hand. Section $\mathbf{2}$ presents the methodology and sources used to build the survey. Then I focus on some major questions about the nature of switchreference. Section 3 lays out the geography of SR, which suggests areal diffusion. Section 4 presents what the survey tells us about what switch-reference tracks. Section 5 analyzes the types of clauses in which switch-reference appears. Section $\mathbf{6}$ concerns the SR morpheme itself, focusing on its form, its location in the clause, and its status as an independent morpheme. The closing section considers an outlook for the future.

2. The survey. The survey investigates 123 languages and dialects in the North American region. I adopt a standard notion of North America as a linguistic area as anywhere in the modern United States and Canada, Mexico north of the Tropic of Cancer, along with all of Baja California, and Greenland. Within that area, I found 69 varieties with switch-reference and five languages which probably have SR but for which a final determination could not yet be made. Table 1 provides a list of all the varieties involved. The actual results of the survey and the source material are presented in the online appendix.

2.1. Structure of the survey. I test each language or dialect for ten major linguistic traits, including 33 different linguistic facts about SR, along

although it is not clear that SR is involved (more needs to be known about the syntax of the languages in Weisemann's article). 
TABLE 1

Language Varieties Examined for Survey ${ }^{1}$

\begin{tabular}{|c|c|c|c|}
\hline \multicolumn{2}{|l|}{ Family } & Variety & ISO Code \\
\hline \multicolumn{2}{|c|}{ Algonquian } & (p) Arapaho & ara \\
\hline \multirow[t]{8}{*}{ (1) } & 8 & Blackfoot & bla \\
\hline & & Cheyenne & che \\
\hline & & Delaware & del \\
\hline & & Maliseet/ Passamaquoddy & pqm \\
\hline & & Menomini & mez \\
\hline & & Miami-Illinois & mia \\
\hline & & Ottawa Ojibwe & otw \\
\hline & & Plains Cree* & cre \\
\hline \multicolumn{2}{|c|}{ Athapaskan } & Chilcotín & $\mathrm{clc}$ \\
\hline \multirow[t]{3}{*}{$(0)$} & 4 & Navajo & nav \\
\hline & & Sarcee & srs \\
\hline & & Slave & den \\
\hline \multicolumn{2}{|l|}{ Caddoan } & Pawnee & paw \\
\hline $\mathbf{0} \quad(0)$ & 2 & Wichita & wic \\
\hline \multicolumn{2}{|c|}{ Eskimo-Aleut } & Central Alaskan Yup'ik* & esu \\
\hline $\mathbf{0} \quad(0)$ & 2 & Inuktitut* & ike \\
\hline \multicolumn{2}{|c|}{ Iroquoian } & Cherokee & $\mathrm{chr}$ \\
\hline \multirow[t]{3}{*}{ 0 $\quad(0)$} & 4 & Mohawk & moh \\
\hline & & Oneida & one \\
\hline & & Tuscarora & tus \\
\hline \multicolumn{2}{|l|}{ Isolates } & Chimariko & cid \\
\hline \multirow[t]{10}{*}{$4 \quad(0)$} & 7 & Haida* & hai \\
\hline & & Mobilian Jargon & $\bmod$ \\
\hline & & Natchez & $\mathrm{ncz}$ \\
\hline & & Seri & sei \\
\hline & & Timucua & $\operatorname{tjm}$ \\
\hline & & Tonkawa & tqw \\
\hline & & Tunica & tun \\
\hline & & Washo & was \\
\hline & & Waikuri & \\
\hline & & Zuñi & zun \\
\hline \multicolumn{2}{|l|}{ Keresan } & Acoma & $\mathrm{kjq}$ \\
\hline 0 $\quad(0)$ & 1 & Santa Ana Keresan & kee \\
\hline \multicolumn{2}{|c|}{ Kiowa-Tanoan } & Isleta (So. Tiwa) & tix \\
\hline \multirow[t]{4}{*}{ (0) } & 4 & Kiowa & kio \\
\hline & & Picurís (No. Tiwa) & twf \\
\hline & & Tewa & tew \\
\hline & & Taos (No. Tiwa) & twf \\
\hline \multicolumn{2}{|l|}{ Maiduan } & Konkow & mjd \\
\hline \multirow[t]{2}{*}{$3 \quad(0)$} & 0 & Maidu & vmv \\
\hline & & Nisenan & $\mathrm{nsz}$ \\
\hline
\end{tabular}

This content downloaded from 129.237.045.148 on December 06, 2016 11:52:52 AM All use subject to University of Chicago Press Terms and Conditions (http://www.journals.uchicago.edu/t-and-c). 
TABLE 1-continued

\begin{tabular}{|c|c|c|c|}
\hline \multicolumn{2}{|c|}{ Muskogean } & Alabama & akz \\
\hline \multirow[t]{6}{*}{ (0) } & 0 & Apalachee & xap \\
\hline & & Chickasaw & cic \\
\hline & & Choctaw & cho \\
\hline & & Creek (Muskogee) & mus \\
\hline & & Koasati (Coushatta) & cku \\
\hline & & Mikasuki & mik \\
\hline \multirow{2}{*}{\multicolumn{2}{|c|}{$\begin{array}{l}\text { Numic } \\
\text { (Uto-Aztecan) }\end{array}$}} & Comanche & com \\
\hline & & Chemehuevi & ute \\
\hline \multirow[t]{8}{*}{ (1) } & 0 & Kawaiisu & xaw \\
\hline & & (p) Mono & $\mathrm{mnr}$ \\
\hline & & Northern Paiute & pao \\
\hline & & Shoshone & shh \\
\hline & & Southern Paiute & ute \\
\hline & & Tübatulabal & tub \\
\hline & & Tümpisa (Panamint) & par \\
\hline & & Ute & ute \\
\hline \multicolumn{4}{|l|}{ Plateau } \\
\hline \multicolumn{2}{|l|}{ Penutian } & Nez Perce & nez \\
\hline $1 \quad(0)$ & 1 & Klamath & kla \\
\hline \multicolumn{2}{|l|}{ Pomoan } & Central Pomo & poo \\
\hline \multirow[t]{5}{*}{ (0) } & 0 & Eastern Pomo & peb \\
\hline & & Kashaya & kju \\
\hline & & Northern Pomo & pej \\
\hline & & Southeastern Pomo & pom \\
\hline & & Southern Pomo & peq \\
\hline \multicolumn{2}{|l|}{ Salishan } & Bella Colla (Núkalx) & blc \\
\hline$(0)$ & 4 & Comox & coo \\
\hline \multirow{2}{*}{$\mathbf{0}$} & & Lillooet (St'atimcéts) & lil \\
\hline & & Musqueam (Upriver & \\
\hline & & Halkomelem) & hur \\
\hline \multicolumn{2}{|l|}{ Siouan } & Assiniboine & asb \\
\hline \multirow[t]{9}{*}{$(0)$} & 4 & Biloxi & bil \\
\hline & & Crow & cro \\
\hline & & Dakota & dak \\
\hline & & Hidatsa & hid \\
\hline & & Kaw (Kansa) & ksk \\
\hline & & Lakota & lkt \\
\hline & & Mandan & $\mathrm{mhq}$ \\
\hline & & Osage & osa \\
\hline & & Ofo & ofo \\
\hline \multicolumn{2}{|l|}{ Takic } & Cahuilla* & chl \\
\hline 0 & 3 & Cupeño & cup \\
\hline & & Kitanemuk & \\
\hline & & Luiseño & lui \\
\hline
\end{tabular}

This content downloaded from 129.237.045.148 on December 06, 2016 11:52:52 AM All use subject to University of Chicago Press Terms and Conditions (http://www.journals.uchicago.edu/t-and-c). 
TABLE 1 -continued

\begin{tabular}{|c|c|c|c|}
\hline \multirow{2}{*}{\multicolumn{2}{|c|}{ Tlingit-Eyak }} & \multirow{3}{*}{$\begin{array}{l}\text { Serrano* } \\
\text { Tlingit }\end{array}$} & ser \\
\hline & & & tli \\
\hline \multirow{2}{*}{\multicolumn{2}{|c|}{$\begin{array}{l}\mathbf{0} \quad(0) \quad 1 \\
\text { Tsimshianic }\end{array}$}} & & \\
\hline & & Coast Tsimshian (Sm’algyax) & tsi \\
\hline \multirow{2}{*}{\multicolumn{2}{|c|}{$\begin{array}{l}0 \\
\text { Utian }\end{array}$}} & & \\
\hline & & Central Sierra Miwok & $\operatorname{csm}$ \\
\hline \multirow[t]{4}{*}{$(0)$} & 4 & Mutsun & \\
\hline & & Northern Sierra Miwok & mwn \\
\hline & & Plains Miwok & pmw \\
\hline & & Southern Sierrra Miwok & skd \\
\hline \multirow{2}{*}{\multicolumn{2}{|c|}{$\begin{array}{l}\text { Uto-Aztecan } \\
\text { (besides Numic) }\end{array}$}} & Eudeve & opt \\
\hline & & Guarijio & var \\
\hline \multirow[t]{10}{*}{ (1) } & 2 & Hopi & hop \\
\hline & & Mayo & mfy \\
\hline & & Névome & pia \\
\hline & & (p) Northern Tepehuan* & ntp \\
\hline & & Ónavas Pima & pia \\
\hline & & Pima & pia \\
\hline & & Sierra Pima & pia \\
\hline & & Tarahumara & $\operatorname{tac}$ \\
\hline & & Tohono O'odham & ood \\
\hline & & Yaqui & yaq \\
\hline \multicolumn{2}{|l|}{ Wakashan } & Nuuchahnulth (Nootka) & nuk \\
\hline $\mathbf{0} \quad(0)$ & 1 & & \\
\hline \multicolumn{2}{|l|}{ Wintun } & Wintu & Wnw \\
\hline $0 \quad(0)$ & 1 & & \\
\hline \multicolumn{2}{|l|}{ Yokutsan } & (p) Buena Vista Yokuts & yok \\
\hline \multirow[t]{9}{*}{ (2) } & 1 & Chawchila Yokuts & yok \\
\hline & & Choinunmi Yokuts & yok \\
\hline & & Chukchansi Yokuts & yok \\
\hline & & Gashowu Yokuts & yok \\
\hline & & (p) Pawelyami Yokuts & yok \\
\hline & & Tachi Yokuts & yok \\
\hline & & Takelma & $\mathrm{tkm}$ \\
\hline & & Wikchamni Yokuts & yok \\
\hline & & Yawelmani Yokuts & yok \\
\hline \multicolumn{2}{|l|}{ Yukian } & Yuki & yuk \\
\hline $1 \quad(0)$ & 0 & & \\
\hline \multicolumn{2}{|l|}{ Yuman } & Hualapai & yuf \\
\hline \multirow[t]{5}{*}{$12 \quad(0)$} & 1 & Ipai & dih \\
\hline & & Kiliwa & dih \\
\hline & & Kumeyaay & dih \\
\hline & & Kwtsaan & yum \\
\hline & & Maricopa & mrc \\
\hline
\end{tabular}

This content downloaded from 129.237.045.148 on December 06, 2016 11:52:52 AM All use subject to University of Chicago Press Terms and Conditions (http://www.journals.uchicago.edu/t-and-c). 
TABLE 1-continued

\begin{tabular}{lc}
\hline Mojave & mov \\
Northern Cochimí & $\operatorname{coj}$ \\
Paipai & $\mathrm{ppi}$ \\
Southern Cochimí & $\mathrm{coj}$ \\
Tipaay (Jamul) & $\mathrm{dih}$ \\
Yavapai (Tolkapaya) & yuf \\
Yavapai & yuf \\
\hline${ }^{1}$ Languages in boldface have switch-reference. Other languages do not. Lan- \\
guages appearing with a (p) before their name probably have switch-reference. \\
Below the name of each group of languages is the count of such languages: \\
those with SR, (those probably having it), and those without.
\end{tabular}

with the values SS or DS. These are listed in figure 1. Each one of these facts addresses research issues that have arisen in the switch-reference literature and I discuss each of these in more detail in the relevant sections of the paper and the relevant parts of the survey.

2.2. Sources. The data in this survey come chiefly from four types of sources: reference grammars, texts published in various sources, journal articles and book chapters, and other books such as dictionaries and text collections.

Reference grammars are obviously a useful source of data. Some of these date to the earliest days of anthropology. Many of the grammars cited here were written in the descriptive surge tied to the Survey of California and Other Indian Languages. More recent grammars contain insightful and in-depth discussions on SR that build on this previous work. Examples include Broadwell (2006) on Choctaw, Martin (2011) on Creek, and Givón (2011) on Ute.

When consulting a reference grammar, I found it helpful to look at the entire work. This process was time-consuming but fruitful, for several reasons. First, the examination of the morphology requires a comparison between clauses with SR and those without. Second, while reference grammars generally have a section devoted to switch-reference, pertinent facts or examples sometimes only appear elsewhere; I had to read accompanying texts to round out information and confirm the analysis. Few descriptive accounts make a point of describing the syntactic distribution of the SR morphemes, especially with respect to tense, aspect, or mood. Thus, it was very informative to see examples of use throughout a text. However, making any determination required some understanding of the verbal morphology of the language, so a perusal of the reference grammar was necessary. The insight from this process is included in the survey, and any errors are mine.

2.3. Beyond the description. The survey relies on descriptive generalizations made by linguists and anthropologists. However, survey information 
(1) What SR tracks, and the list of the morphemes themselves (see $\mathbf{4}$ in text/part 1 of the survey)

(a) (canonical) same subject

(b) (canoncial) different subject

(c) (non-canonical) co-referent

(d) (non-canonical) disjoint

(2) The SR morphemes themselves (part 1 of the survey)

(3) Referential issues: What does SR mark when these arise? (see $\mathbf{6 . 2}$ in text/part 1 of the survey)

(a) inclusion: one argument includes the other

(b) overlap: plural arguments intersect

(c) ambient/weather/expletive subject

(d) quantified or non-referential subject

(4) Morphological exponence of SR, with respect to morphology in the "verbal spine" (see

6.2 in text/ part 2 of the survey)

(a) fusion with verbal morpheme

(b) replacement of verbal morpheme

(c) linear placement after verbal morpheme

(d) linear placement before verbal morpheme

(5) Homophony with some other morpheme in the language (see 6.1.2 in text/part 2 of the survey)

(6) Position of the SR marker in the clause (see 6.2.2 in text/part 3 of the survey)

(a) on the right or left edge of the clause

(b) at the very edge, or merely part of the edge word

(c) not at the edge

(7) Sub-clausal types: when SR appears in a structure whose English equivalent is not a complete clause (see $\mathbf{5 . 2}$ in text/part 3 of the survey)
(a) auxiliaries
(b) wh-verbs
(c) quantificational verbs
(d) pro-verb/recapitulative verb

(8) Clause types: what type of clauses does the SR marker appear at the juncture of? (see $\mathbf{5 . 1}$ in text/part 3 of the survey)
(a) coordination
(b) clause-chaining
(c) adverbial
(d) complement
(e) relative/nominalized
(f) conditional

(9) The translation of the sentential connective on the SR-marked clause (see $\mathbf{5 . 1}$ in text/ part 2 of the survey)

(10) Position of the SR-marked clause with respect to the dominant clause (see 5.1.3 in text/ part 3 of the survey)

(a) preceding the dominant clause

(b) following the dominant clause

(c) center-embedded

(11) Effects of SR on SR-clause verbal morphology (see $\mathbf{6 . 3}$ in text/part 2 of the survey)

FIG. 1 
sometimes relies on deducing SR from the descriptive content. In other cases, the lack of SR can be deduced despite the description. This process requires consistent criteria. The criteria used in this investigation are based on the definition of SR given in $\mathbf{1 . 1}$ above. ${ }^{5}$ I declare a morpheme as switch-reference only if it typically or always exhibits the following properties: $(a)$ it occurs at or near a clause juncture; $(b)$ it has two values in a complementary pair-i.e., the morphemes have the same meaning except SR; $(c)$ the value it expresses depends on the reference of the subjects or prominent arguments, and none of their other features. For instance, SR ignores the person or gender of the subjects. Morphemes meeting at least two of these criteria warrant inclusion in the survey, pending more detailed investigation.

2.3.1. Switch-reference before SR. Deduction of SR is necessary for descriptions published before Jacobsen (1967), some of which have laid out what are essentially SR systems. The earliest case I found is Riggs's $D a$ kota Grammar, first published in 1893, which obviously has no section on switch-reference, and the discussion of the grammar often requires a bit of deciphering into modern terminology. However, by looking at the section on complex clauses, I was able to discern apparent SR marking on coordinating conjunctions $k a([\mathrm{kPa}])$ and $u \eta k a \eta$, as shown in (4).

(4) SR-bearing conjunctions in Dakota

(4a) ekta wai ka wandamka

(4b) ekta wai uykay waymayakapi
'I went and saw'

'I went there and they saw me'

Riggs (1893/2004:78) writes of these conjunctions: "When two or more verbs having the same nominative are connected by a copulative ${ }^{6}$ conjunction, $k a$ is commonly used, as [in $4 a$ ]. But if a new nominative is introduced, uykay will be required, as [in $4 b]$."

His account strongly suggests switch-reference in Dakota conjunctions, especially compared to the SR-marked conjunctions in closely related Lakota na (SS) and yũkhã (DS) (Dahlstrom 1982 and Lungstrum 1995). The Dakota conjunctions meet all three criteria, so I include them in the main survey.

From the discussion and the examples, the probability that Dakota has (or had) a SR system is high enough to warrant its inclusion in the main survey. Examination of the texts included in the grammar buttresses this conclusion. Note, however, that examination of the texts also reveals non-canonical usage of DS marking, at points where it can be expected based on its use in Lakota and other languages (see $\mathbf{4 . 1}$ below). Thus, Riggs's use of "commonly" is not surprising.

\footnotetext{
5 This definition is largely based on McKenzie (2012:1).

${ }^{6}$ Riggs's sense of COPULATIVE does not involve a modern sense of copula but rather a broader sense that we would today call "connective."
} 
Later, anthropologists discovered complementary pairs of morphemes in various languages. Kroeber (1911:369) wrote of the Yuki conjunctions sa and si: "They form a contrasting pair. Sã indicates that the subject of the sentence which it opens is the same as the subject of the preceding sentence. $\mathrm{Si}$ indicates a corresponding change of the subject." $\mathrm{He}$ is also the first to note one of the most widely observed uses of SR: "These two particles enable the speaker to narrate at great length complicated and varying reciprocal actions of two persons, without any designation of them, either noun or pronoun, after their first mention."

Sapir (1930:244-46) essentially discovered a switch-reference system in Southern Paiute. Writing in 1917, he described different subordinating markers as what we would now call SS or DS. About -t.sl, its "logical subject is always the same as that of the main clause." About -kka-, which has the same meaning as $-t \cdot s l$ except for SR, Sapir found that its "subject is different from that of the main clause."

The earliest description that explicitly classifies morphemes as same- or different-subject is Voegelin's (1935) grammar of Tübatulabal. Voegelin lays out a system of suffixes that "have correlative meanings, and differ only in that in one type, the subject of the main verb and the subordinate verb are identical; while in the other type, the subject of the main verb and the subordinate verb are not identical" (1935:123).

Given descriptions as precise as these, it was rather easy to include these languages in the main survey. Unfortunately, despite this early work, the similarities between these systems went unnoticed for decades.

2.3.2. Languages described as having $S R$ which actually lack it. Examination of the sources not only found cases of SR that had not been explicitly described but also discovered cases where languages described as having SR do not actually seem to have it. By and large, I adopted researchers' judgments on whether a morpheme involved switch-reference. However, there were cases that warranted a second look.

For example, Bascom (1982) claims that sentential conjunctions in Northern Tepehuan mark for SR-dai marks SS while tai marks DS. Bascom's summary is very clear and would meet all the criteria, but an examination of the examples and accompanying texts revealed no use of tai at all, and many uses of dai with different subjects. Mindful of non-canonical switchreference (4.1), I found that the use of purportedly SS-marking dai with different subjects does not seem to reflect cases of typical non-canonical SS use. Thus, it seems that this language does not in fact have switch-reference. However, I list it as "probably" having SR, since further description might show that it does have it.

Besides Northern Tepehuan, three other cases of doubtful SR merit mention, because they are from papers specifically arguing for switch-reference. Two involve languages from the Eskimo-Aleut family. Woodbury (1983) describes 
the "fourth-person" pronouns in Central Yup'ik Eskimo as switch-reference. However, these do not meet any of the criteria. Besides, our understanding of these pronouns fits better with obviation systems and long-distance anaphors-that is, this is not switch-reference. ${ }^{7}$

Pittman (2005) argues about Eastern Canadian Inuktitut that the participial marker -llu is an SS marker, while -ti-llu marks open reference-it works with identical or disjoint subjects. This pair does meet two criteria ( $a$ and c), but I have argued elsewhere (McKenzie 2012) that switch-reference is very unlikely, in part because even Pittman proposes that these are temporal markers. The lack of any clearly reliable account of SR in either Inuktitut or Yup'ik leads me to treat them as if they do not have it.

A third case of doubtful SR comes from the Algonquian language Plains Cree. Muehlbauer (2012) argues that the morpheme -yi- marks DS, contrary to claims that it is part of the obviation system. He notes that it only appears when the subject of the -yi- marked verb is disjoint from that of the connected verb. Examples like (5) are certainly suggestive.

(5) Obviation marking in Plains Cree (Muehlbauer 2012:216)

(5a) nâpew atimw-a wâpam-ê-w [ê-sipwêhtê-t]

man dog-OBV see-DIR-3 c-leave-3

'The $\operatorname{man}_{\text {prox }}$ saw the $\operatorname{dog}_{\text {obv }}$ as he $e_{\text {prox }}$ (the man) left'.

(5b) nâpew atimw-a wâpam-ê-w [ê-sipwêhtê-yi-t]

man dog-OBV see-DIR-3 C-leave-yi-3

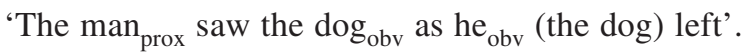

However, - $y i$ - does not meet any of the criteria. The morpheme fails criterion $(a)$ because while it appears on verbs with obviative subjects, it also appears on possessed nouns with obviative possessors. SR never affixes to nouns.

$$
\begin{array}{llll}
\text { cân } & \text { wâpam-â-w } & \text { o-stês-a } & \text { o-îk-yi-ihk } \\
\text { John } & \text { see-DIR-3 } & \text { 3-older.sibling-oBv } & \text { 3-house-yi-LOC } \\
\text { 'John } & \text { prox } & \text { saw his } \\
\text { hrox } & \text { older brother }{ }_{\text {obv }} \text { at his } & \text { obv (the brother's) } \\
\text { house' } & \text { (Muehlbauer 2012: 217) }
\end{array}
$$

It fails criterion $(b)$ because there is no complementary SS marker. Most importantly, it fails criterion $(c)$. The morpheme only concerns itself with subjects, but it is also sensitive to person and perspective. It does not appear with first- or second-person pivots or anti-pivots. Moreover, Muehlbauer argues that $-y i$ - marks a third-person argument in the joined clause which

\footnotetext{
${ }^{7}$ Another non-SR language involving pronouns is Haida. Enrico (2003) describes as switchreference the appearance or non-appearance of third-person subject pronouns in embedded clauses. Since this does not involve any new morphemes, and is person restricted, it does not meet the criteria here.
} 
possesses a perspective on the event (2012:220-21). He claims that the morpheme is thus a type of SR marker, but it has properties of morphemes involved in obviation.

So what is it? I suspect that -yi- simply signals that a predicate has an obviative subject or possessor. That suspicion is based on the generalization that every subject of a $y i$-marked verb is obviative. ${ }^{8}$ The fact that $-y i$-marking is not allowed at the beginning of a discourse, or in a superordinate clause (Cook 2008), was offered as evidence of SR. However, the examples provided had not established any argument as proximate, so introducing an obviative in these contexts is already ruled out. Consequently, $-y i$ - is impossible. We can derive the apparent SR effect of $-y i$ - by taking a different perspective on Muehlbauer's characterization of $-y i-:$ By marking an outside argument's perspective, $-y i$ - signals that its verb's subject is third person and not proximate. Thus, it is obviative.

The Plains Cree morpheme -yi-, purported to denote switch-reference, does not meet any of the criteria provided. Therefore, I claim the language does not have switch-reference. One way to test for certain would be to set up a series of joined clauses where the subjects are co-referent and obviative-marked. If $-y i$ - is a DS marker, it should not appear on the verbs. If it is a marker of obviative subjects, it should appear.

2.4. Summary. This survey involves data from dozens of languages. The data were trawled from reference grammars, articles, texts, and dictionaries. Some languages were added to the main survey despite not being explicitly described as having switch-reference, while others were removed despite explicitly being described as having it, reflecting the value of testing descriptive claims to ensure their cross-linguistic consistency before making typological claims. Testing is especially valuable with a term like swiTcHREFERENCE, which has been used in many different ways since it was coined. What follows are the major findings collected from the survey, organized by the questions concerning switch-reference that the survey addresses and the revelations it provides.

3. Where switch-reference is found. This section discusses the geography of SR in North America. While table 1 lists all the languages

${ }^{8}$ Note that the converse is not true-not every verb with an obviative subject is -yi-marked. The source of the restrictions surely varies and warrants investigation. It might be the case that $-y i$ - signals that the thematically highest argument in the clause is obviative, given Muehlbauer's example (3) (example 5 above). It has an obviative subject and proximate object, and the verb is not -yi-marked.

My suspicion is constrained by the fact that it is based solely on the Plains Cree data in Muehlbauer's paper, chapter 4 of Cook (2008), and Déchaine and Wiltschko (2002:434), who have an example. 


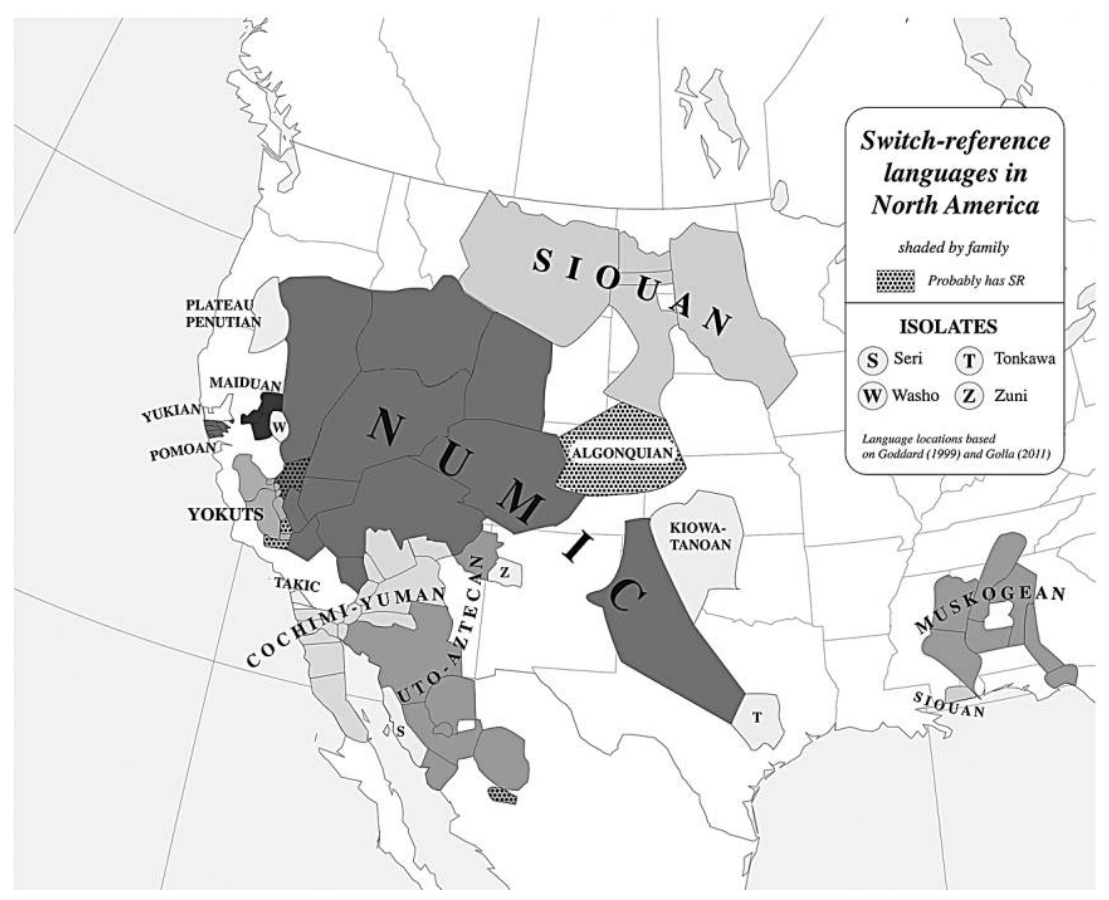

FIG. 2.-Map of switch-reference languages in North America.

surveyed, the map in figure 2 shows the locations of those with SR, shaded by family. Since the Uto-Aztecan family is so broad, I have listed the Numic and Takic subgroups separately.

SR languages are spread throughout 11 families and four isolates. The languages include all the examined members of the (Cochimí-)Yuman, Muskogean, Maiduan, and Pomoan families, as well as all the Numic group but Mono (which is probable). In the case of the Muskogean and Yuman families, the SR morphemes are generally cognates and were perhaps present in each respective proto-language. Other groups with at least some members are Yokutsan, Plateau Penutian, Yukian, Takic, Kiowa-Tanoan, and Siouan.

SR is not found in other families. Jacobsen (1983) found no SR morphemes in 32 languages examined. This survey finds no SR in 40 languages of the Algonquian, Athapaskan, Caddoan, Eskimo-Aleut, Iroquoian, Salish, Tlingit-Eyak, Tsimshianic, Wakashan, and Wintun families. These language families cover most of the rest of the continent, except the parts of the present eastern United States whose populations died or dispersed before any records were kept. 
Most strikingly, figure 2 shows that SR languages are nearly all in the west and southwest of the continent. The clustered geographic distribution of SR languages was observed right away (Jacobsen 1967), and a similar clustering has been observed in Australia as well (Austin 1981). On both continents, the distribution strongly suggests that areal diffusion is involved in the spread of switch-reference.

One strong piece of evidence for areal diffusion is that with SR, geography often trumps family. For instance, among the Siouan languages, only those on the Northern Plains-near areas of contact with Numic speakers-developed SR. The only exception is Biloxi, whose speakers lived in contact with Muskogean speakers. ${ }^{9}$ At an even finer-grained level, Lakota and Dakota have SR, while the closely related Assiniboine does not. Among the Takic languages, only Luiseño and Cupeño have switch-reference. ${ }^{10}$ Klamath is the only Plateau Penutian language with SR. Kiowa is the only Kiowa-Tanoan language with SR. McKenzie (2012) suggests an explanation for Kiowa's SR based on Kiowa history. While most Tanoan language speakers lived in the Rio Grande valley, the Kiowas migrated along the western edge of the Great Plains (see figure 3). Along the way, they formed close alliances with the Crow and later the Comanche, both of whose languages have switch-reference. The adjacency and intermixing may have led to the diffusion of SR. ${ }^{11}$

This section has discussed the major facts concerning the distribution of SR languages in North America. They are almost all in the west, in a mostly contiguous geographic area. Also, many language families only have one or two members that have SR; these members are in that contiguous area. These facts support previous observations that areal diffusion has played a role in its cross-linguistic distribution. Of course, the full role of geography in the spread of SR is forever shrouded by the lack of documentation on many of the languages, especially in the Western Gulf region. Still, the survey reveals valuable information about the distribution of switch-reference. The following sections discuss the properties of the phenomenon itself, focusing

\footnotetext{
9 To explain why the Athapaskan and Algonquian languages in the West do not have switchreference, Jacobsen suggests that their obviation systems make it unnecessary. However, Hopi has both switch-reference and obviation, and Hale (1992) even argues for their inclusion under one system. Perhaps we can hypothesize that obviation reduces the odds of areal spreading of SR, without fully eliminating them.

${ }^{10}$ Jane Hill (personal communication) has informed me that Takic languages Serrano and Cahuilla do have SR, while Kitanemuk and Tongva (now extinct) were not described in enough detail to know.

${ }^{11}$ One of the Kiowa SS markers, [tsẽ :], greatly resembles the Comanche SS marker [tsi] . Perhaps it was borrowed directly, with a vowel change driven by Kiowa phonotactics, which rules out [tsi] or [tsi] (Watkins 1984:11).
} 


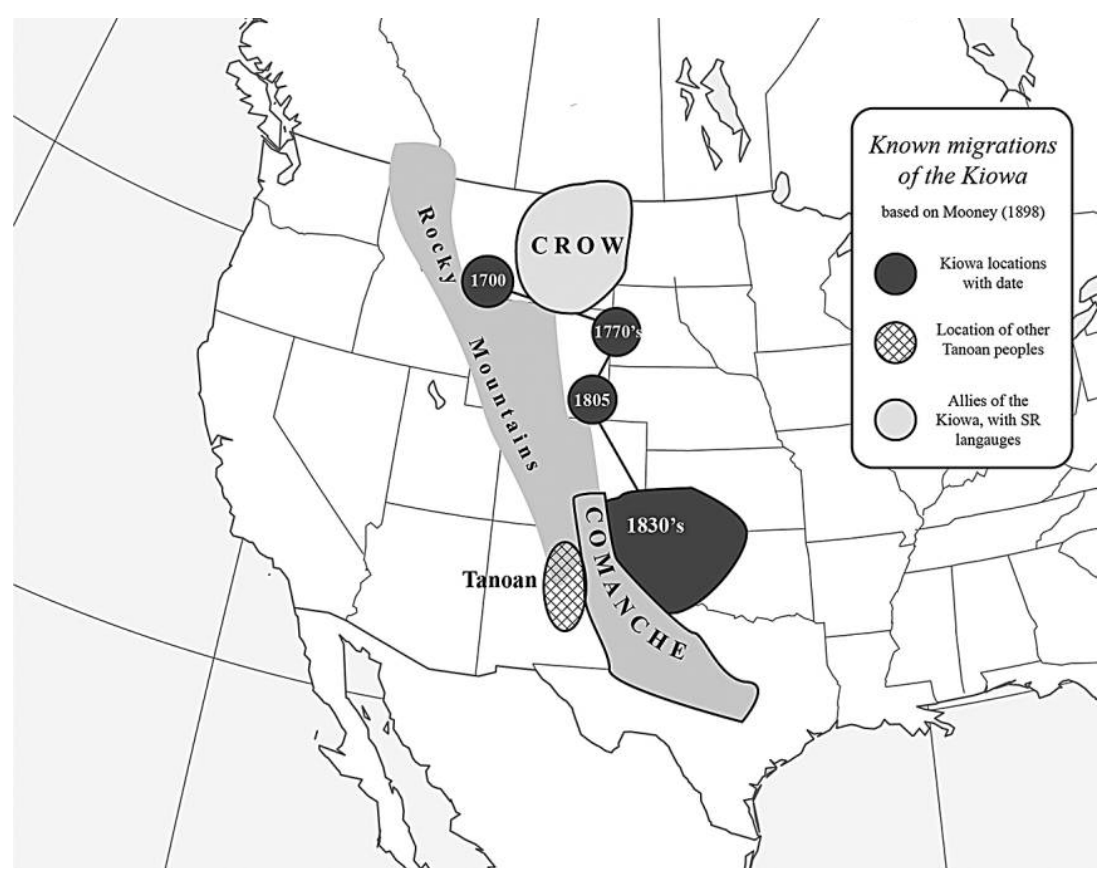

FIG. 3.-Map of Kiowa migrations.

on what the survey teaches us about the structure, form, and function of switch-reference.

4. What switch-reference tracks. To understand the basic nature of switch-reference, we need to answer three broad questions, which roughly cover different modules of the grammar. First is the semantic question: What does switch-reference track? Second is a syntactic question: What types of clauses does it appear in? The third is morphological: What forms does it take and how does it interact with the morphology? I address these questions in detail below.

The first and perhaps most important of these questions is the nature of what switch-reference tracks. That is, what exactly is co-reference SR marking? Jacobsen's first observation (1967) was that SR tracked the reference of the subjects of the joined clauses, indicating whether or not they were co-referent. This observation has formed the basis for much research, especially since the 1990s. That research discovered that switch-reference does not always track subjects, and that the nature of co-reference becomes fuzzy when we consider plural and non-referential subjects. 
4.1. Non-canonical switch-reference. As (2) above demonstrated, non-canonical switch-reference (NCSR) ignores subjects. Another example of NCSR comes from Kiowa, where SS marking can be used, even if the subjects are clearly distinct individuals:

(7)
Kathryn gya-gút
go
Esther=al gya-gút
K.
3sA:PO-write:PF
and:SS E.=too
3sA:PO-write:PF

'Kathryn wrote a letter and Esther wrote one too'. (Watkins 1993:147-48)

Non-canonical DS marking can be used, even if the subjects are clearly identical, as this example from Mandan shows:

(8) kipxeak kirątErị kasi:wịowąko?š kirųwą?kšis

$$
\begin{array}{lll}
\text { ki-pxe-ak } & \text { ki-rątE-ri } & \text { ka-si:-wi-o:wąk-o?š } \\
\text { MV-land-DS } & \text { MV-getup-SS } & \text { ICPT-travel-PROG-NPST-PMA } \\
\text { ki-rųwą?k-ši-s } & \\
\text { ?-man-good-DEF }{ }^{12} &
\end{array}
$$

'Coyote landed, got up, and started traveling'. (Mixco 1997:240)

Most of the recent attempts to understand switch-reference focus on NCSR, in the hopes of answering the question: If SR tracks co-reference, and noncanonical SR ignores subjects, what is it tracking? SR has never been observed in North American languages to track objects, applicatives, or any nominal arguments except subjects, ${ }^{13}$ and none of the languages in this survey allows tracking of any nominal argument except a subject. ${ }^{14}$ So what does non-canonical SR track?

Most generalizations of NCSR suggest that it "tracks" continuity of a scene, rather than subject co-reference (Dahlstrom 1982, Roberts 1988, Mithun 1993, Watkins 1993, Rising 1992, and Martin 2011). Non-canonical SS marking is found when it highlights the coherence of the two clauses- the SS marking in (7) is appropriate when the letter-writing events are linked in some way, perhaps by a plan. Non-canonical DS marking is often found at the boundary between two parts of a narrative, to signal an episodic shift. In (8) it signals

12 The 'good man' is an epithet here for Coyote.

13 A reviewer points out that the Australian language Warlpiri (ISO code: wbp) is claimed to have "same" SR markers that vary based on whether the matrix argument co-referent to the embedded subject is matrix subject, object, or neither (Austin 1981 and Legate 2002).

${ }^{14}$ In Choctaw, subject-marked external possessors can be tracked, but they seem to be external subjects (Broadwell 1997; 2006).

$\begin{array}{lllll}\text { (a) John-at } & \text { im-ofi' } & \text { im-illi-tok-oosh, } & \text { nokhakklo-sh } & \text { bínniili-h } \\ \text { John-NOM } & 3 \mathrm{~s}-\mathrm{dog} & \text { 3sD-die-PST-SS } & \text { sad-SS } & \text { sit-TNS }\end{array}$

'Because John's dog died, he's sad'. 
a shift in the narrative from the events leading up to the fall to the events subsequent to getting up. ${ }^{15}$ Stirling (2001) also lists NCDS appearing with shifts from direct to indirect reports and "change in action or focus of action."

Analyses of NCSR attempt to derive this sense of continuity-tracking in different ways. Stirling (1993) proposes that SR signals event "agreement" by tracking the reference of the protagonist, location, and actuality of the joined clauses' event arguments. This includes canonical and non-canonical SR. More recently, I have proposed (McKenzie 2012) that canonical SR tracks subject co-reference, while non-canonical SR tracks co-reference of Austinian topic situations, which refer to the part of a possible world that the sentence is about. Non-canonical SS indicates that the two sentences are about the same part of a world, while non-canonical DS indicates the sentences are about different parts of a world.

Both Stirling's and my theories draw on what is known about non-canonical $\mathrm{SR}$ in a number of languages-however, this is not much. Few languages have been studied in enough detail for this survey to support strong claims about the target of non-canonical SR. That would require further research on individual languages. Thus, the survey ignores the targets of NCSR and focuses on the morphemes used. It lists SR morphemes by their attested value (SS or DS) and their canonicity. If a morpheme is ever not used with the value expected based on subject-tracking, it is listed under the SS or DS column under "noncanonical." If it is only used canonically, it is listed under "canonical."

Some researchers have proposed a third possible value for SR morphemes, called "open reference," whereby the SS marker cannot be used with disjoint subjects, but the DS marker can be used with co-referent subjects (Munro 1983 and O'Connor 1993). The Northern Pomo example in (9) demonstrates DS marking despite co-referent subjects.
(9) tiyi
ša-nam
ma?a-kan
ma:dal
yat-ye
LOG fish-DET eat-because:DS
3s:FEM:PAT vomit-PST

'She vomited because she ate the fish' (O'Connor 1993:232)

The survey does not make room for open reference; instead, any use of DS with identical subjects is listed as non-canonical DS marking. Before accepting a diagnosis of open reference, we need to verify that these cases do not have non-subject pivots. The survey does not completely rule out the possibility of open reference, but the question requires further research.

4.2. When reference is not so simple. Besides tracking non-subjects, switch-reference often tracks subjects whose reference or co-reference is not clearly understood. It also tracks subjects that do not refer at all. The survey

15 Since long stretches of recorded speech in most Native American languages have primarily been narratives, little work has been done on non-canonical SR outside of narratives, but see Watkins (1993) and McKenzie (2012) for examples from extemporaneous speech or elicitation. 
lists behaviors associated with these kinds of subjects in the few languages where data have been collected or analyzed.

4.2.1. Partial co-reference. When two plural subjects are fully identical, they trigger SS marking. Fully disjoint, they trigger DS marking. However, when they are partially identical, some languages require SS, some DS, and some allow either. This variation was a key feature of descriptive studies of switch-reference in the 1970s, although it fell out of favor later. Yet the question is still interesting, especially in light of more recent work in morphosyntactic theory focused on the link between expressed syntactic features and semantics. This survey includes information about languages where partial co-reference was described, or when I came across examples of it in the source material.

The survey splits partial co-reference into two types: overlap and inclusion (part 1). Overlap occurs when the subjects intersect, as in We $e_{1,2}$ came in and you.PL $L_{2,3}$ sat down. No survey languages were found to allow SS marking, but few have been examined - only three are known to require DS.

Inclusion occurs when one subject contains another, as in $W e_{1,2}$ came in and $I_{1}$ sat down. Many languages require DS marking, while only seven are attested to allow SS marking. Stirling (1993) discusses typological claims concerning how languages allowing inclusive SS vary on whether the pivot includes the anti-pivot or vice versa. Stirling points out that many languages only allow inclusive SS if the pivot contains the anti-pivot. This is marked in the survey under "inclusion" as SS* and only includes Zuñi here. Many languages allow inclusive SS also if the anti-pivot contains the pivot (marked as SS,SS*). Four languages in the survey do: Kumeyaay, Mojave, Maricopa, and Kashaya. According to Stirling, no language is observed to allow it ONLY if the anti-pivot contains the pivot (marked as SS). However, both Cocopa (Langdon and Munro 1979:325) and Maidu (Oswalt 1976:299) may be counterexamples, since they are only attested as such.

It should be noted that no survey language is found to REQUIRE SS marking with inclusion. In some cases (e.g., Kumeyaay), no positive evidence was found for inclusion with DS marking, but no negative evidence ruled it out either. Languages where DS is used with the pivot containing the anti-pivot are marked as DS*, while DS indicates that an anti-pivot containing the pivot triggers DS marking.

Overall, when it comes to partial co-reference in North American SR, we know little. This lacuna hinders strong claims based on North American languages. It is possible that what we see as inclusive or overlapping SS marking is actually non-canonical SR - until the pivots are actually determined, we cannot say much with certainty.

4.2.2. Non-referential subjects. Another problem involving reference is that many subjects do not refer. The survey explores two types of non-referential subjects: ambient or expletive subjects (It's raining), or quantificational 
subjects, notably negative subjects (Nobody is home). If a subject does not refer, how does a reference-tracking system deal with it? Few languages have been studied with regard to this. Those that have show that ambient subjects vary and quantified subjects behave as if they were referential. Langdon and Munro (1979) discuss SR with weather verbs. Their results are included in the survey. Non-referential subjects were not discussed in detail until my work (McKenzie 2011; 2012). I found that SR treats these as if they referred. ${ }^{16}$ For example, in (10a), from Kiowa, SS marking is found with a bound reading of the embedded subject, while DS marking is found with a referential reading $(10 b)$.

(10a) Háun hájél èm gúnmà̀uchè̀ èm dấujà̀ugù.

hõn hátél [ẽm-gún-mõ:=tsẽ̃:]

NEG person/INDEF 3sA:RO-dance-IMPF=when:SS

ẽm-dó:+to:-gu

3sA: $\mathrm{RO}-$ sing + act-NEG

'Nobody ${ }_{1}$ sang while they ${ }_{1}$ danced'.

(10b) Háun hájél èm gúnmà̀uè èm dấujà̀ugù.

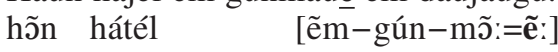

NEG person/INDEF 3sA:RO-dance-IMPF=when:DS

ẽm-dó:+to:-gu

3sA: $\mathrm{RO}-$ sing + act-NEG

'Nobody ${ }_{1}$ sang while he/she ${ }_{2}$ danced'. (McKenzie 2012:239)

This distribution makes sense under the idea that quantifiers like nobody can bind a variable to derive "co-referent" readings that occur with SS marking. The SS marking is redundant, yet still required by the grammar. When the pivot subject is not bound $(10 b)$, the sentence has a referential reading, and the pivot and anti-pivot are disjoint. DS marking occurs as expected.

While the evidence is clear for Kiowa, no other language has been specifically examined in this respect. In some cases, I found examples of SR with a quantificational or ambient subject. Any types found are listed in the survey by the value of SR that happened to occur.

4.3. Conclusion. This section has discussed what switch-reference tracks. It does not always track subjects and, often, the referentiality of the subjects is non-existent or not clear. These facts are crucial in understanding what switch-reference is and what it means, and they form a prominent part of the survey.

16 A reviewer points out that Stirling (1993) discusses "impersonal subjects" in Amele (ISO code: aey), where subjects are referential object-marked experiencers that are picked up by SR. In these cases, SR is not tracking anything non-referential. 
5. The structure of SR-marked clauses. One of the important structural issues concerning switch-reference is the structural types of pivot clauses. This question has been crucial to theories of switch-reference, for two reasons. First, any theory of SR must be compatible with all the observed clause types. Second, restrictions on clause types might shed light on other properties of SR. Indeed, such restrictions are often the starting point of theories for switch-reference. Jacobsen's survey addressed the issue of structure in broad strokes. This survey refines the questions, building on our improved understanding of syntax. It shows that canonical switch-reference is not linked to any particular type of clause and reinforces findings that non-canonical SR is restricted to coordination and clause-chains.

5.1. Clause types and the structure of switch-reference. The question concerning the nature of the clauses became prominent after Finer $(1984 ; 1985)$ proposed that SR was an A-bar-pronoun subject to a generalized Chomskyan binding theory. The use of a binding theory required that the pivot clause be subordinated to the anti-pivot clause, because it required c-command. At the time, coordination was held to involve a flat structure that precluded c-command. Thus, Finer concluded that all pivot clauses were subordinating.

This claim was already a bit difficult to maintain for the languages Finer examined, but Roberts (1988) showed that SR-marked clause-chains in New Guinea languages passed various tests for coordinating structures. Broadwell (1997) argued that Choctaw clause-chains failed tests for coordinating structures but passed those for subordinating structures.

The survey shows that the controversy is moot. SR in North America occurs with all types of clause connectives, except for or (see part 3 of the survey). Even if there were not all this data to settle the issue, theoretical perspectives render it moot as well. Munn (1993) showed that sentential coordination must involve syntactic subordination and c-command. Also, examinations of clause-chaining structures (Stirling 1993 and Miller 2001) find them sometimes coordinating and sometimes subordinating, even within the same language. The rest of this section discusses the behavior of SR with each of these structures.

5.1.1. Switch-reference on coordination. SR occurs with sentential coordination in ten of the surveyed languages. Given that coordinating conjunctions form a constituent with the second conjunct, we can assume that this constituent is the pivot clause (PC), while the first conjunct is the antipivot clause (APC). Figure 4 shows how SR works with coordination. At each juncture $\left(\operatorname{SR}_{n}\right)$, the pivot $\left(P_{n}\right)$ is in the SR-clause and the anti-pivot $\left(A_{n}\right)$ is in the previous clause. If $A n=P_{n}, S R_{n}$ will show SS. If not, it will show DS. Each subsequent juncture works the same way. Notably, in each case, the pivot of one clause is the anti-pivot of the next. 


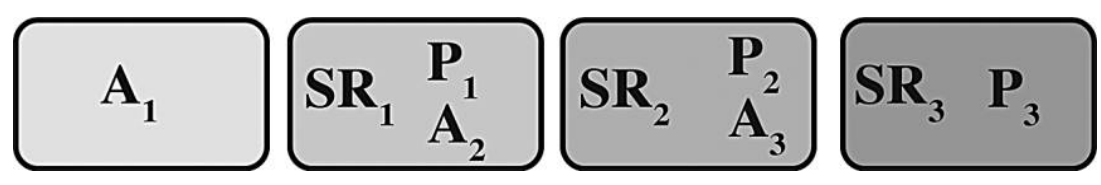

FIG. 4.-Schematic of SR with sentential coordination.

SR with coordination also works across sentence and speaker boundaries, as the Kiowa examples (11) and (12) demonstrate. The sentence boundary in (11) is marked by prosody and a distinct pause. The existence of some kind of clause juncture is still deduced from the connective; however the exact nature of that connection is an open question.

(11) Dáu ấu.

Gìgáu èm hốài.

dó-ố: | go-hegó ēm-hó:+a:j

agr-give.PF full stop and.SS-then 2s-travel+start off.PF

'You gave it to us. And then you left'.

(12) Switch-reference across speaker boundary in Kiowa

(12a) A: Cútà̀dau dáut ắu.

kút+a:də dót-ó:

write+stick 3sA:3IO:1pD-give.PF

' $\mathrm{He}_{4}$ gave us a pencil.'

(12b) B: Gàu éèè̀l é é áu.

$\begin{array}{lll}\text { go } & \text { ë́de=al } & \text { é-ó: } \\ \text { and.SS } & \text { this=also } & 3 \mathrm{sA}: 3 \mathrm{sD}: 1 \mathrm{sO}-\text { give.PF }\end{array}$

'And he 4 gave me this'.

In part 3 of the survey, languages are marked as using coordination under the heading "clause types." The conjunction is always in the clause-initial word, so it is marked in this heading with an I (for initial). If SR is at the outer edge of the initial word, the clause type is marked with an asterisk ( I*).

5.1.2. Switch-reference on subordination. SR occurs very frequently on subordination, occurring in 45 languages in the survey. SR with subordination is clearly hierarchical, rather than linear (Gordon 1983, Finer 1984, and Munro 2005). That is, when two pivot clauses are subordinated to the same clause, they also share an anti-pivot. This is represented schematically in figure 5, where $\mathrm{SR}_{1}$ and $\mathrm{SR}_{2}$ share the matrix anti-pivot $\left(\mathrm{A}_{1,2}\right)$.

A feature of SR with subordination is that the SR appears to "skip" linearly adjacent clauses. An example is (13), from Maricopa (Cochimí-Yuman, Arizona).

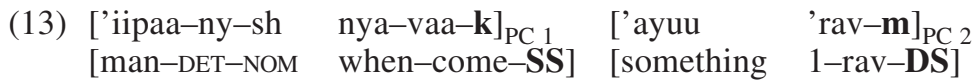




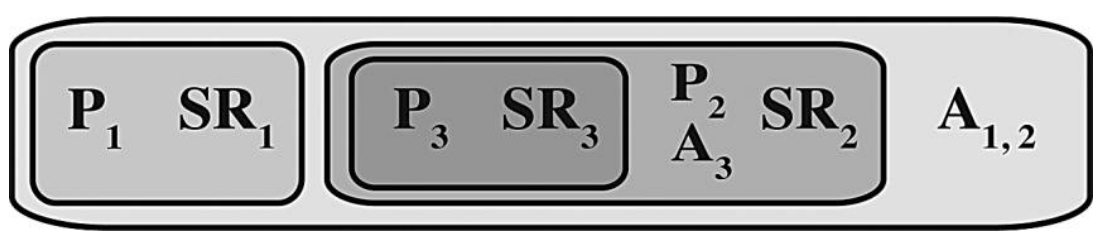

FIG. 5.-Schematic of SR with subordination.

$$
\begin{aligned}
& \text { ny-wik-k } \mathrm{k}_{\mathrm{APC}} 1,2 \\
& \text { 3A:1O-help-ASP }
\end{aligned}
$$

'When the $\operatorname{man}_{1}$ came, he 1 helped me because I was sick' (Gordon 1983:98)

(Lit., 'The man came-SS/something hurt me-DS/he helped me')

In (13), there are three clauses. The first two are both subordinate to the third. The subject of the first clause (PC 1), 'iipaanysh 'the man', is disjoint from that of the second clause (PC 2). But it co-refers to that of its dominant clause (APC 1,2), and we see SS marking. The subject of the second clause is disjoint from that of the main clause, so PC 2 bears DS marking.

SR morphemes that involve subordination are listed under headings that reflect the type of subordination. The exact meaning of the connective is listed in the heading "translation." 17 The survey divides subordinating SR clause types by broad categories of meaning. The most common type is adverbial, followed by complement clauses, then relative clauses and conditional clauses. Adverbial clauses are those translated by connectives like when, as, while, before, after, because, or purpose clauses. In most American languages with SR on subordination, the subordinating SR morphemes are on the final word, so they are marked with an F. In some languages, they are on the verb, so they are marked with V. If they are also the final morpheme in the clause, they are marked with an asterisk $\left(\mathrm{F}^{*}\right)$. No languages put SR on clause-initial subordinating connectives.

5.1.3. Placement of subordinate pivot clauses. There is no crosslinguistic restriction on the placement of subordinate pivot clauses relative to their anti-pivot clause. They can be left-located (preceding the anti-pivot clause), right-located (following it), or center-embedded. The survey treats left-location as a sort of default and does not signal it overtly. This choice stems from practical concerns rather than any theoretical choice-left-located pivot clauses are far more commonly described than the other types.

17 In some cases, I standardized the terminology concerning connective meaning. For instance, while Sapir (1930) describes a morpheme expressing that the embedded clause event precedes the main clause event as ANTECEDENT, I use the term SEQUENTIAL $(\mathrm{p}<\mathrm{ap})$, which I use elsewhere as well. $(\mathrm{p}<\mathrm{ap})$ means that the pivot clause action temporally precedes the anti-pivot clause action. 
Many languages allow the pivot clause to linearly follow the anti-pivot clause. This is marked in the survey with an $\mathrm{x}$ in the entry for clause type. For instance, Choctaw complement clauses can be right-located (14) or leftlocated, so they are indicated by an (x) under "complement clause." The parentheses signal optionality. No language is observed to require right-located subordinate pivot clauses.

$$
\begin{aligned}
& \text { (14) Lynn-at ik-ikháan-o-h [iy-aachi-ka-t]. } \\
& \text { Lynn-NOM AGR-know:L-NEG-TNS go-IRR-COMP-SS }
\end{aligned}
$$

Pivot clauses in many languages are center-embedded. Center-embedding is marked in the survey with a $\mathrm{c}$ in the entry for clause type. Languages that allow both center-embedding or postposing are marked as (x,c). Parentheses signal optionality, and no language requires center-embedded pivot clauses. Chickasaw complement clauses provide one example of this type of positioning.

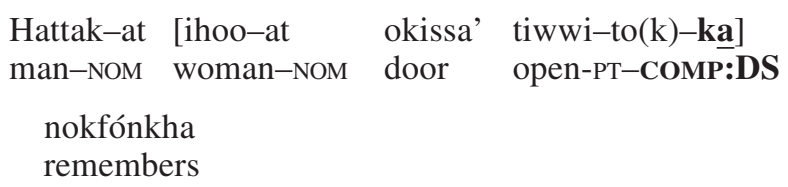

'The man remembers that the woman opened the door.' (Munro 2005:140)

5.1.4. Switch-reference on clause-chains. Switch-reference is often found on the structure known as clause-chains. Clause-chains involve a series of verb-final "medial" clauses with defective or stripped-down morphology, terminated by a "final" clause with full mood and tense marking. For example, in (16), from Central Pomo, there are three clauses, but only the final verb is aspect-marked. The other verbs must be interpreted with the same tense and aspect.

$$
\begin{aligned}
& \text { Pa: čáw=yó-ba máti ?-čchá:-č-ba ma?á } \\
& \text { 1A in=go-SS down by.gravity-Sit-INCH-SS food } \\
& \text { qa:-yú?č’i-w } \\
& \text { biting-begin-PF }
\end{aligned}
$$

'I came into the house, (I) sat down, and (I) started to eat'.

(Mithun 1993:121)

When a clause-chaining language has SR, the marker is always at the end of a medial clause. The pivot is in the medial clause, and the anti-pivot is in the next subsequent clause, whether medial or final. See figure 6.

With respect to switch-reference, clause-chains behave more like coordination than subordination. However, it is not clear what the exact nature of their clause connection is. In many respects, medial clauses seem subordinate, 


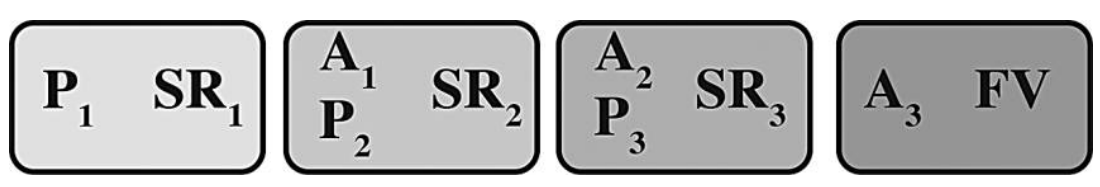

FIG. 6.-Schematic of SR with clause-chaining.

because they must have the same mood and tense as the final clause. However, Roberts (1988:52) points out that in the New Guinea language Amele, negation in an initial chain can scope over the other chains. Foley and Van Valin (1984) go further, proposing a third type of clause connection they call "co-subordination." Ultimately, a clear understanding of the structure of clause-chains awaits, so for this survey, SR on clause-chains is listed under the clause type "chain."

5.1.5. Typological generalizations. The survey does confirm my (McKenzie 2012) generalization that non-canonical switch-reference only appears with coordinating or clause-chaining structures. ${ }^{18}$ In addition, however, we can conclude that the presence of switch-reference is not tied to any type of connective. It appears on coordination, subordination, and clause-chains. Any generalized theory of switch-reference needs to be compatible with all of them.

At the same time, relatively few languages have SR on more than one type of connective. Kiowa, Tohono O'odham, and perhaps Northern Paiute use it on coordination and subordination. Biloxi and Eudeve use it on coordination and clause-chains. More common is the use on clause-chains and subordination-16 languages do this, notably in the Muskogean and Pomoan families. Only Eudeve allows it on all three types. The other 47 only allow it on one type.

5.1.6. Concerns about translations. Determination of the clause type is made difficult by the translation of the connective. Sometimes, a single structure or morpheme is translated from an SR language in several different ways, depending on the speaker's or the linguist's interpretation. The translations have different syntactic structures, but we must not assume that the original expressions have different structures.

For example, in Jamul Tipaay, SR marking occurs only on clause-chains, but the chains can be translated in English as a single clause (17a), an embedded question $(17 b)$, or a control clause with purpose interpretation (17c), among others.

18 To be more precise, I argue (McKenzie 2012) that NCSR only appears with clauses that contain an Austinian topic situation pronoun. Some syntactically subordinating clauses may contain such an argument and ought thus to allow NCSR. 
(17) Differing interpretations of Jamul Tipaay clause-chains (Miller 2001:240)

(17a) w-amp-ch

$$
\text { 'al' al-ch }
$$$$
\text { w-aam-s }
$$

3-walk-SS wobble-SS

3-go.away-EMPH

'He staggered away'

(17b) chaw-k uuyaaw-x

fix-IRR:SS knOw-IRR

'I will find out how to fix it (or, I will know how and I will fix it)'

$\begin{array}{llll}\text { servees } & \text { me-si-X-pu } & \text { m-aa-chm } & \text { uuyaaw } \\ \text { beer } & 2-\text { drink-IRR-DEM } & \text { 2-go-DS } & \text { know }\end{array}$

'I know you went there to drink beer'

It may be the case that the clauses in (17) actually do have different structures. However, we simply cannot tell from the translations alone. Cases like Jamul Tipaay were common (also see Langdon 1970:153). Thus, while the translations are listed in the survey, they should not be assumed to be definitive statements about the language in question without consulting the sources more thoroughly.

5.2. Subclausal switch-reference? Another problem with translation occurs when pivot clauses are translated as part of a larger single clause. Switch-reference is universally thought to occur between two "complete" clauses, so its occurrence within a single clause would be an important discovery. Thus, the survey lists any cases where SR occurs in a structure translated as a single clause. The survey presents 36 languages with structures that might be monoclausal. Under each of the "subclausal types," any observed values of SR are recorded. It is probable that the structures are in fact biclausal or are monoclausal vestiges of older SR systems. Translations can be treacherous, so their inclusion is more a guidepost for researchers than a claim about the structures involved.

5.2.1. Verbal quantifiers. Many Native American languages have quantifiers that are verbs, rather than nouns or adverbs. Instead of saying 'Two men came in', one might say something literally like 'The men two'ed and they came in'. Thus, a biclausal structure in a Native American language gets translated as monoclausal in English. Creek is one such language; in (18), the SS marking 19 shows that the men who numbered two were those who came back.

19 Martin (2011) glosses SS as -T and DS as -N. These are homophonous with case markers (nominative and oblique, respectively). Martin suggests that SR and case are two uses of a single thematic marker. He does not motivate this suggestion, but it is an uncontroversial assumption in the Muskogeanist literature. I changed these glosses for clarity in this paper. See 6.1.2 for more discussion about case homophony with SR. 
$\begin{array}{llll}\text { (18) honan-tá:ki } & \text { hokkô:l-os-it } & \text { 1-ala:hóhk-it } & \text { o:k=â:t } \\ \text { man-PL } & \text { two:F-DIM-SS } & \text { DIR-arrive:DU:H-SS } & \text { say:L=REF }\end{array}$

'Only two men came back, and said ...' (Martin 2011:315)

In (19), the DS marking shows that the person numbering one is not the person making someone a judge.

(19) ísti person one-DS judge-ACC make:H-AGR-SS ...

'We'll make one person the judge...' (Martin 2011:315)

(Lit., 'A person will [number] one and we will make him judge')

5.2.2. Verbal wh-words. Similar facts are found with other types of interesting verbs. Many Native American languages employ special verbs to ask wh-questions. This example from Choctaw has DS marking since the subject is apparently expletive ('why is it that ...').

$\begin{array}{lll}\text { Kátiimi-h-o } & \text { kaniiy-aachi-h } & \text { miya- } \mathrm{h} \text { ? } \\ \text { Q-TNS-PTCP:DS } & \text { go.away-IRR-TNS } & \text { hearsay-TNS }\end{array}$

'Why is he going away?' (Broadwell 2006:109)

5.2.3. Anaphoric pro-verbs. Another common structure that appears to be subclausal involves pro-verbs, which are anaphoric morphemes that refer to the previous clause. Pro-verbs are also called recapitulative verbs, or anaphoric particles, in the literature. They are usually fixed or reduced forms of the verbs for 'be' or 'do', as in this example from Tonkawa.

(21)

\begin{tabular}{lll} 
hostaxso:n & \multicolumn{2}{c}{ xilipa:nanoklakno?o } \\
in the morning & he always went out hunting:EVID \\
ha:Pako:nwa:a:la. & ?e:lilia & ?aweykak \\
that man & he so doing:SS & many deer \\
$\mathrm{k}^{\mathrm{w} a}$ a:lowkak & ya:lo:nanklakno?o & \\
big ones & he always killed them:EVID
\end{tabular}

'That man went out hunting every morning, it is said. So doing, he always killed many big deer, it is said'. (Hoijer 1949:43)

In the survey, if a language has pro-verbs, the observed values of SR on those pro-verbs are listed. One would expect either SS or DS to occur as freely on a language's pro-verbs as it does on its clause connectives. However, in many of the languages, only one or the other was observed. This observation might simply be due to a lacuna in the reference grammars, since few discussed pro-verbs and SR together. The lack of negative evidence in each case means that the other may be possible, pending further investigation.

SR-marked pro-verbs are always sentence-initial. However, they can be analyzed as one-word clauses with clause-final SR marking. One typological generalization emerges: SR use on pro-verbs occurs only in languages where 
SR does not occur on sentential coordination. This observation suggests that pro-verbs might provide a work-around that allows the semantic equivalent of switch-reference across conjoined clauses (see 5.1.1 above).

5.2.4. Auxiliaries. Many SR languages require SS morphemes between main verbs and auxiliaries. This feature is especially notable in Yuman languages. For example, in Hualapai, the main verb carries subject/object agreement, while the auxiliary only carries subject agreement and carries tense and mood marking. SS marking separates the verb and auxiliary.

(22) Mach misma:kmyu.

$\begin{array}{ll}\text { ma-ch } & \text { mi-sma:- } \mathbf{k}=\mathrm{m}-\mathrm{yu} \\ \text { you-NOM } & 2-\text { sleep-SS=2-be } \\ \text { AUX }\end{array}$

'You are sleeping' (Watahomigie et al. 2001:75)

Auxiliaries are one among several phenomena which seem at first glance to involve the use of switch-reference within a single clause, rather than across a clause boundary. However, it is unlikely that auxiliary structures synchronically involve switch-reference. They always require SS marking, and there is not a second subject. Instead, the auxiliary structures were probably biclausal in the past but later reanalyzed as auxiliaries. The SS marking is undoubtedly merely a vestige of the former SR system.

5.3. Summary. This section has described the different types of clause structures that SR is found with. The question of clause types has long sat at the heart of theoretical analysis of the phenomenon, in the hopes of using structural facts to shed light on the meaning and function of SR. However, these discussions generally focus on a single language at a time. The survey demonstrates that SR is found with all types of clause junctures. It also shows SR in many structures that seem to be monoclausal but which are actually biclausal or do not contain synchronic systems of switch-reference. This structural diversity is important for theories of switch-reference. Most theories, from Finer (1984) through Keine (2013), make strong claims that restrict the types of connectives that SR can appear on. However, this survey shows quite clearly that apart from canonicity, neither the meaning nor the structure of SR is inherently tied to any type of connective. And this survey only covers one continent.

6. The morphology of switch-reference. The final major issue this paper addresses is the morphology of switch-reference. This involves three basic questions: First, what is the form of the SR morpheme? Second, where is the SR morpheme situated in the pivot clause? Third, what effects does the presence of SR have on other verbal morphemes? The survey confirms that SR morphemes only express one of two values. They are often thought of as a paradigm, but many SR systems show interesting asymmetries. The 
TABLE 2

Some Homophonies BetweEn SR and CASE MoRphemes

\begin{tabular}{llllll}
\hline \hline Group & Language & SS & Case & DS & Case \\
\hline Muskogean & Choctaw & $-t$ & nominative & $-\tilde{\mathrm{v}}$ & accusative \\
& Creek & $-(i) t$ & nominative & $-(i) n$ & oblique (acc) \\
Numic & Ute & $-y u$ & some nom* & $-k u$ & some acc* \\
& Kawaiisu & $-y u$ & some nom* & $-k u$ & some acc* \\
& & & locative, & & ablative, \\
Yuman & Yavapai & $-k$ & cislocative & $-m$ & translocative \\
& Tipaay & $-c h$ & nominative & $-m$ & ablative \\
\hline
\end{tabular}

${ }^{*}$ These languages have multiple sets of case markers; SR is homophonous with one set.

survey also reveals that SR morphemes in many languages are homophonous with other morphemes in the language, too many to be a coincidence. Answers to these issues might open up new avenues for understanding the nature and the origin of switch-reference morphology.

\subsection{Form of the SR morpheme.}

6.1.1. Paradigms. Switch-reference is expressed as one of two values. SS marking occurs when the pivot and the anti-pivot co-refer. DS marking occurs when the pivot and the anti-pivot are disjoint. ${ }^{20}$ This characterization can apply no matter what the pivot is argued to be. SS and DS originally stood for "same subject" and "different subject," reflecting their subject-tracking function. Even though SR does not track solely subjects, the abbreviations are still used.

In the survey, each morpheme is listed under its value in a standardized IPA format, to aid in comparison. Any transliteration errors are mine. We can see that most pairs of SS and DS morphemes are in complementary distribution. However, some languages only have DS marking (e.g., Washo, Seri). No languages in the survey have only SS marking.

6.1.2. Homophony. In many languages, complementary pairs of SR morphemes are homophonous with some other complementary pair. The most salient homophonies involve case marking. In many Yuman languages, SS $-k$ is homophonous with allative case, while DS $-m$ is homophonous with a case that one could call ablative - it marks motion away, instrumental, and comitative. In many Muskogean languages, SS $-t$ matches nominative case, while DS - $n$ matches accusative/oblique case. Table 2 includes some instances of homophony in Native American languages. The data suggest an interesting link between case and SR.

${ }^{20}$ See discussion about possible "open reference" in 4.1. 
This striking homophony is not limited to the Americas. Austin (1981) found case/SR homophonies in Australian languages as well. The homophony has led to many suggestions of a common semantic core between case marking and switch-reference. Some analyses go further, treating case and SR as the same morpheme in different domains (Kendall 1976, Rising 1992, Ichihashi-Nakayama 2004, and Camacho 2010, among others). As a result of this literature, homophony is given its own heading in the survey. I list cases of homophony mentioned by the source, and I also list cases discovered by looking through the reference grammars or texts. In that process, not all homophonies were judged as equal. As an example, from the Yuman language Cocopa, the DS suffix $-m$ is listed as homophonous to comitative case suffix $-m$ but not to second-person agreement prefix $m$ -

The amount of homophony is surely not a coincidence. However, while homophony in a particular language or family is striking, it is hard to generalize. Cross-linguistic extension of any proposal that SR has a strong link to case would have to be reconciled with the fact that many SR languages lack case marking altogether, while many SR languages with case have no homophony. Also, as table 2 shows, there is significant variation in the case values that SS and DS are homophonous with. In Muskogean languages, the opposition is nominative/accusative. In some Yuman languages, the opposition is near/far, while in others, it is nominative/ablative. If SR is tied to case, which cases is it tied to? If there is a semantic core, does the meaning of SR change from one language to another?

More importantly, SR morphemes in many languages are homophonous with other morphemes not related to case. In Maricopa (Gordon 1983), SS and DS match different realis markers. In Crow (Graczyk 2007), SS matches a subject relativizer affix, while DS matches an indefinite article. ${ }^{21}$ In Tohono O'odham, the conjunctions marking SR are homophonous with participials.

In addition, even languages with case homophonies present difficulties. In Choctaw, for instance, there is a second set of SR markers, -cha ([t $\left.\int \mathrm{a}\right]$ ) and $-n a$, which are not homophonous with anything. Hopi has a complementary pair on relative clauses, $-y$ ([j]) for SS and $-t$ for DS. Each is homophonous with a different accusative case marker. The Biloxi DS marker matches an accusative marker, but the SS marker does not match anything. Cocopa and Alabama have case homophonies but also an additional SS marker that is not homophonous with anything.

21 This homophony becomes even more evident when narratives are considered. In narratives, the DS marker $-m$ is replaced by -dak (or its allomorph -lak). The same substitution occurs with the indefinite article $-m$ in narratives. Outside of narratives, $-m$ marks non-specific indefinites and -dak marks specific ones. In narratives, -dak marks both. 
All these facts suggest that language-particular case homophonies have some source besides a common semantic core with switch-reference. What is that source? There are several possibilities, perhaps all in play. I suggested one possibility in McKenzie (2012): Homophony arises through a combination of areal diffusion and what I call "exaptation." Essentially, one language borrows switch-reference from another but does not borrow the actual morphemes. Instead, it applies some salient complementary pair of morphemes already in the language, "exapting" it from its old use for a new use with SR. Case is a common target for exaptation because of its salience. A process like this has been observed with areal diffusion of SR in Australia (Austin 1981), expletives in Yiddish (Prince 1998), and of evidentials in Amazonia (Aikhenvald 2004), so its presence in switch-reference in North America should not be a major surprise.

Another possibility is that the SR markers and case markers have distinct etymologies that have been obscured by phonological change. This possibility is suggested by the Muskogean language Mikasuki (Boynton 1982). In Mikasuki, the SR markers are DS -in and SS -ik. Another SS marker, -it, is used only between a verb of saying and the direct quotation. The case marking is -on for accusative and -ot for nominative. Even setting aside -ik, the case and SR morphemes are clearly distinct. However, Boynton (1982:171) observes that she could not distinguish case from switch-reference in rapid consultant speech. This particular case might simply stem from the linguist's own phonology interfering with observation, but it suggests the possibility that the morphemes, once clearly distinct, were becoming uniform by vowel reduction. Perhaps in other Muskogean languages, this reduction happened long enough in the past to obscure any difference.

A third possibility is that the SR markers developed from the case markers, or vice versa. Jack Martin (personal communication) has suggested that the case markers in Creek may have emerged from the use of SR on quantifier verbs (see 5.2.1 above). We can see why when we consider the translationssubjects of SS-marked quantifier verbs are translated as subjects (18), while those of DS-marked clauses are translated as objects (19). This usage would have been reinterpreted as case marking on nominal quantifiers, then extended to referential nouns. Zigmond, Booth, and Munro (1991) suggest this for the Numic language Kawaiisu. The Kawaiisu SR markers featured in table 2 are only found on numerals and quantifiers, and might not even be SR anymore. The Ute SR markers in table 2 have the same distribution as the Kawaiisu ones and may have undergone the same process.

Each of these possibilities is plausible - and more defensible from a historical and theoretical standpoint than the stronger proposal of a semantic link between case and switch-reference. Unfortunately, confirming them would require a more thorough understanding of the historical development of the 
languages in question, and it is almost certain that no materials will ever emerge that would allow us to achieve that.

6.2. SR morphemes in the pivot clause. The location of SR morphemes in the pivot clause is also important for understanding SR morphology. This property is divided into three axes: the particular morpheme inside the pivot clause that SR is associated with (tense, complementizer, etc.), the linear location of SR within the pivot clause, and the type of connective. The type of connective was discussed in the section on clause types (5.1). The rest of this subsection considers SR's position relative to other morphemes in the extended verbal projection.

6.2.1. The morpheme $S R$ is associated with. SR is usually found with or as part of some other verbal or sentential morpheme, such as a particular complementizer. For each SR morpheme, I list its association under the heading "morphological exponence," in part 2 of the survey. The exponence of SR morphemes has rarely been addressed in the literature, but it is crucial to have a sense of it if we are to develop accurate theories of switch-reference, because any theory of switch-reference needs to find a place for the morpheme in the phrase structure. Most analyses place it on the complementizer or conjunction $\left(\mathrm{C}^{\circ}\right)$, while I (McKenzie 2012) place the SR morpheme at its own functional head $\left(\mathrm{SR}^{\circ}\right)$, lower in the extended verbal projection. The lower placement predicts that SR should be found associated with morphemes besides $\mathrm{C}^{\circ}$. The survey confirms this prediction.

In this discussion, I assume the standard generative notion of extended verbal projection (EVP). The EVP refers to a series of functional heads and their projected phrases, each of which provides information typically classified as "verbal": T(ense), Asp(ect), M(ood), Neg(ation), and so on. A typical hierarchy of these heads is in (23), which shows their location dominating the verb phrase, which includes the arguments. The presence of an EVP is a sign of a "complete" clause, and in connected clauses, there is a C(omplementizer) head as well.

\section{$\left[\mathrm{CP} \mathrm{C}^{\circ}\left[\mathrm{TP}^{\circ}\left[\mathrm{NegP} \mathrm{Neg}{ }^{\circ}\left[\mathrm{AspP}^{\mathrm{Asp}}{ }^{\circ} \mathrm{VP}\right][\right.\right.\right.$}

In many languages, these morphemes end up on a single word or even fused together. This collocation is the result either of linearization, agreement, or head movement.

The survey shows SR associated with several different morphemes. In Kiowa, it is fused with the complementizer or conjunction. In (24), the complementizer cliticizes to the rightmost constituent in the pivot clause.

(24) John é zón cútădàuchè , é têm.

$\begin{array}{lll}\text { [John } & \text { é-zốn } & \text { kút+á:də]=tsẽ: } \\ \text { [J. } & \text { 3sA:3IO-pull.out:PF } & \text { write+stick]=when:SS }\end{array}$


é-tễm

3sA:3IO-break:PF

'When John pulled it out, the pencil, he broke it (in two)'.

(McKenzie 2012:56)

In the survey, fused SR morphemes are listed in the morphological exponence column as "F(used)," underneath the morpheme they are fused with. In some cases, the exponence is R(eplace), when the SR does not or cannot co-occur with the morpheme in question. SR fuses with complementizers in many languages, but the survey shows quite plainly that SR is not always fused with $\mathrm{C}^{\circ}$. For instance, SR fuses with tense in Luiseño, mood in Mandan, and aspect in Tolkapaya. This variety supports McKenzie's placement of SR morphemes below the $\mathrm{C}^{\circ}$ head.

More evidence for a low placement is that SR morphemes in some languages are not concatenated with complementizers at all. This is the case in Yuman languages, where a subordinating prefix attaches to the verb, while SR is postverbal. In Hualapai, this prefix is nyi-. In (25a), there is no subordinator, and a clause-chain like structure leads to an interpretation of coordination. In (25b), nyi- appears, and the pivot clause is interpreted as a manner adverbial.

(25a) Johnach gwèviyá, gwa:mk Banyà:nyuwál wa:mkwiny

$$
\begin{array}{lll}
\text { John-ch gweviyam } & \emptyset \text {-gwa:m-k } & \text { Banya:nyuwa-1 } \\
\text { J.-NOM car } & \text { 3A:3O-drive-SS } & \text { Phoenix-into } \\
& \emptyset \text {-wa:m-k=wi-ny } & \\
\text { 3A:3O-take:SS=do-PST } &
\end{array}
$$

'John drove the car and took it into Phoenix'.

(25b) Johnach gwèviyá, nyigwa:mk Banyà:nyuwál wa:mkwiny

$$
\begin{aligned}
& \text { John-ch gweviyam nyi- Ø-gwa:m-k Banya:nyuwa-1 }
\end{aligned}
$$

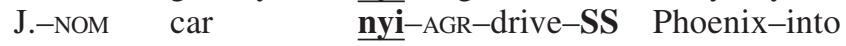

$$
\begin{aligned}
& \emptyset \text {-wa:m-k=wi-ny } \\
& \text { AGR-take:SS=do-PST }
\end{aligned}
$$

'By driving the car, John took it into Phoenix'. (Watahomigie et al. 2001:424)

In Yuman, the SR morpheme still forms part of the same phonological word as the complementizer. But in some languages, complementizers are clause-initial, while SR is clause-final. This is the case in the Takic languages, including Luiseño. ${ }^{22}$

\footnotetext{
22 Subjects of subordinate clauses in Luiseño are possessive-marked, as are subjects of clauses with auxiliary verbs.
} 
TABLE 3

Choctaw Switch-Reference-Bearing Complementizers

\begin{tabular}{lll}
\hline \hline Gloss & SS Form & DS Form \\
\hline 'that'/'when' & $-k a t$ & $k \underline{a}$ \\
'when & $-h m a t$ & $-h m \underline{a}$ \\
'if' & $-k m a t$ & $-k m \underline{a}$ \\
'that/for' & - oosh & $-\underline{-}$ \\
'because' & -haatokoosh & - haatoko \\
'although' & -ohmakoosh & -ohmahko \\
'but' & -ookakoosh & -ookako \\
\hline
\end{tabular}

(26) $\frac{\text { to:wili }}{\text { if }}$

$$
\begin{array}{lll}
\text { punéči-viča-qala } & \text { póyk } & \text { nu-vindé:r-vuta-q } \\
\text { his:pay-want-SUB:DS } & \text { him:DAT } & \text { my:sell-can-PRES }
\end{array}
$$

'If he wants to pay for it, I can sell it to him'. (Davis 1973:183)

More common are languages whose SR morphemes concatenate with $\mathrm{T}^{\circ}$ or $\mathrm{C}^{\circ}$ but are clearly distinct from them. In Choctaw, the SS marker $-t /-s h$ and the DS marker $-\tilde{\mathrm{V}}$ (written as $\mathrm{V}$ ) are easily distinguished in table 3 , adapted from Broadwell (2006:264).

Morphemes that are clearly distinct from some verbal morpheme are listed in the morphological exponence columns as coming A(fter) or B(efore) whichever verbal morpheme they are listed under. Some are listed under multiple columns, like Seri - $t a$, which occurs after verbs with or without overt agreement. It is listed as A under both $\mathrm{V}$ and Agr.

6.2.2. Location of $\mathbf{S R}$ in the pivot clause. Another aspect of an SR morpheme is its location within the pivot clause. This feature is listed in the survey by a key letter under "clause types" and was discussed in $\mathbf{5 . 1}$ above. For the most part, SR morphemes are found at the edge of the pivot clause or at least attached to the right- or leftmost word (such as a clause-final verb). If the SR morpheme is in or attached to the clause-initial morpheme, its letter is I. If it is in or attached to the clause-final morpheme, its letter is F. If the SR morpheme is at the edge of its clause, the letter is marked with an asterisk: $\mathrm{F}^{*}$ or I*.

SR morphemes are typically at the edge of the clause. However, the survey shows that in several languages they are not. For instance, in Seri, SR morphemes can be followed by an "unspecified time" morpheme that seems to broaden the meaning of when to whenever or if. ${ }^{23}$

\footnotetext{
(27) He hptahahásaquim

ma $\mathrm{x}$, ihoqueepe.

1st 1s:RLS:PASS:comb.hair.of DS UT 1s:TR:EMPH:like

'I like it when my hair is combed'. (Marlett 2013:132)

${ }^{23}$ Marlett (2013) notes that $x$ was long written as a suffix, but his consultants thought it was a separate word.
} 
In a handful of languages, SR morphemes are not always on the clause edge. In Yokuts and the Takic languages, SR is attached to the verb, but the verb is not always final. When this occurs, the exponence is listed as V. For instance, in Yawelmani Yokuts, the SS marker -tin ([ $\left.\mathrm{t}^{\mathrm{h} i n]}\right)$ stays on the verb.

$\begin{array}{llll}\text { ['ama' } & \text { wot-tin } & \text { 'amin ] } & \text { kakwiy-hin } \\ \text { he } & \text { hit-PASS:SS } & \text { by.him } & \text { cackle-PST }\end{array}$

'and, being hit by him, he cackled'. (Newman 1944:138)

6.3. Effects on pivot clause morphology. One piece of information that might shed light on the structure of switch-reference is the verbal morphology of the clause. Pivot clauses in many languages are morphologically distinct from anti-pivot clauses. Specifically, they lack certain morphemes from the extended verbal projection-tense, aspect, sometimes even agreement. These differences are listed in part 2 of the survey under "reduced verbal morphology." For instance, many pivot clauses do not have their own tense marking and must be interpreted with the tense of the main clause. This is the case in Cupeño. ${ }^{24}$

(29)

$$
\begin{aligned}
& \text { Me [chixinga pe' } \\
& \text { and if } \\
& \text { pe-miyax-wen } \\
& \text { 3s-be-PST }
\end{aligned}
$$

'And if she spat well, then it was good' (Hill 2001:409)

None of the languages have pivot clauses with more complete verbal morphology than anti-pivot clauses. What is not clear, though, is whether SR is responsible for the reduction in verbal morphology, or if it is an independent feature of the embedded clause.

Pivot clauses also affect the expression of the subject. In some languages, SS pivots are never expressed. In others, pivots are marked with cases other than subject case. For example, in Numic languages, overt pivots are objectmarked. In Yokuts languages, they are possessive-marked. These subject effects are not listed in any heading of the survey. Instead, they are mentioned as notes for individual languages, because it is not clear that SR itself is responsible.

6.4. Asymmetries. The survey reveals a number of asymmetries in switch-reference paradigms. The first is one that Jacobsen also detected: in many languages, the SS and DS morphemes do not form a complementary pair of morphemes which are syntactically and semantically identical except for SR. Complementary pairs are listed in the survey in a single row; non-complementary morphemes are listed in their own row. One

\footnotetext{
${ }^{24}$ In (29), the complementizer is initial and the DS marker is verb-final but not clause-final.
} 
non-complementary pair comes from Tohono O'odham (Hale 1983), where SR appears on conjunctions. The SS marker $c$ [t $\left.\int\right]$ is fused with the conjunction. Meanwhile, the DS marker, $k u$, serves as a host for the pivot clause auxiliary clitic.

In some cases, the members of complementary pairs do not have the same syntactic characteristics. In Crow, for instance, DS-marked clauses allow ordinary plural-subject marking on verbs. SS verbs do not allow this marking, even if the subject is plural. In Central Pomo (Mithun 1993), some of the six switch-reference morphemes are clitics, while their complements are affixes. For instance, - in and $=d a$ correspond to each other, as SS and DS, with the meaning of 'and, while, because'. But one is an affix and one is a clitic.

These asymmetries are interesting and may provide interesting data for theories of morphosyntax. They do not rule out the concept of switch-reference as a paradigm, because such asymmetries are common in the morphemes of the extended verbal projection. For example, aspectual marking in English is synthetic in the simple forms ( $r a n)$ and periphrastic in the progressive forms (was running). Intra-paradigmatic syntactic differences with SR probably arise from accidents of linguistic history (Hale 1983) or from differences in the morphemes that SR happens to be fused with.

6.5. Two more generalizations. Two other morphological generalizations that do not fit elsewhere are mentioned here. First, there is no language in the survey where SR is a prefix or proclitic. The only case where SR is word-initial is in Tohono O'odham, where the DS marker $k u$, fused with the conjunction, can host enclitics. Second, there are no languages in the survey where SR fuses with or conditions subject agreement morphology, the way it does in many New Guinea languages (Roberts 1997). It does concatenate with agreement in some languages, as part of the word containing the verb.

6.6. Conclusion. This section focused on the morphology of switchreference. It only appears in SS or DS form, and most languages have them in complementary pairs. In some languages, especially the Yuman and Muskogean languages, the SR markers are homophonous with some case marking. This fact is often thought to show a common core between the two phenomena, but the survey shows otherwise. More plausible explanations can be offered, though not confirmed. SR morphemes are found near the edges of the pivot clause, though not exclusively. We thus cannot define SR as being AT the juncture of two clauses but rather only as ASSOCIATED wITH the juncture. In a cross-linguistic sense, SR fuses or concatenates with most morphemes in the extended verbal projection but not negation and evidentiality. The morphemes SR does associate with must be present in the pivot clause, but negation and evidentiality are not. Also, SR does not condition agreement paradigms. These generalizations tell us a lot about switch-reference, although many gaps still remain. 
7. Looking ahead. The survey provides a snapshot of the current results of research on switch-reference in North American languages. It opens up new avenues for exploring the phenomenon descriptively and theoretically. By providing a broad basis to test predictions, it also shapes the space of hypotheses in the formulation of theories of switch-reference. It also serves as a template for new surveys in other areas of the world, especially South America, which has never been surveyed, or Australia, which was last surveyed by Austin (1981). In that regard, the survey is not meant to be set in stone. Plans are to make an online version accessible to the public at all times. This public survey can be added to as new information becomes available.

This paper has covered the major current questions about switch-reference, especially from a descriptive standpoint. Typologically, we find that SR is found with all types of clause connections except or, and that it is found associated with several different verbal spine morphemes. Geographically, we find it almost exclusively in the western United States and Mexico, where it has frequently spread by areal diffusion. Semantically, we find that it usually indicates subject co-reference across clauses but not always.

The survey also makes a methodological point about typological work. When looking to see if a particular language exhibits a particular phenomenon, one must first check the definition used in the source material, to see if it matches the one being used. One cannot simply look for the term "switchreference," copy a table, and be done with it. I say this not to impugn linguists of the past but merely to remind researchers of the present and future, linguist or not, who rely on this methodology for broad-based statistical studies. The findings here highlight the fact that definitions change from one source to another, especially for a phenomenon like switch-reference, which has been described and defined in a number of ways over a number of frameworks. Theorists and typologists alike need to be mindful.

This survey provides a better cross-linguistic sense of what switch-reference tracks, how the SR morphemes behave, and the types of clauses they appear in. It will, I hope, aid future research on the subject. This research may better complete linguists' comprehension of switch-reference and help speakers and teachers gain a conscious awareness of how they use it. They may well discover much to add to the discussion.

\section{REFERENCES}

Aikhenvald, AleXandra. 2004. Evidentiality. Oxford: Oxford University Press.

Austin, Peter. 1981. Switch-reference in Australia. Language 57:309-34.

Bascom, Burton. 1982. Northern Tepehuan. Uto-Aztecan Grammatical Sketches, ed. Ronald Langacker, Studies in Uto-Aztecan Grammar, vol. 3, pp. 267-393. Dallas: Summer Institute of Linguistics and University of Texas at Arlington.

Boynton, Sylvia S. 1982. Mikasuki grammar in outline. Ph.D. dissertation, University of Florida, Gainesville. 
Broadwell, George Aaron. 1997. Binding theory and switch-reference. Atomism and Binding, ed. Hans Bennis, Pierre Pica, and Johan Rooryck, pp. 31-49. Dordrecht: Foris. . 2006. A Choctaw Reference Grammar. Lincoln: University of Nebraska Press.

CAmacho, José. 2010. On case concord: The syntax of switch-reference clauses. Natural Language and Linguistic Theory 28:239-74.

Cook, Clare. 2008. The syntax and semantics of clause-typing in Plains Cree. Ph.D. dissertation, University of British Columbia, Vancouver.

DAнLstrom, Амy. 1982. A functional analysis of switch-reference in Lakhota discourse. Papers from the Eighteenth Regional Meeting of the Chicago Linguistic Society, ed. K. Tuite, R. Schneider, and R. Chametky, pp. 72-81. Chicago.

Davis, John Frederick. 1973. A partial grammar of simplex and complex sentences in Luiseño. Ph.D. dissertation, University of California, Los Angeles.

Déchaine, Rose-Marie, and Martina Wiltschko. 2002. Decomposing pronouns. Linguistic Inquiry 33:409-42.

ENRICO, John. 2003. Haida Syntax. Vol. 2. Lincoln: University of Nebraska Press.

FINER, DANIEL. 1984. The formal grammar of switch-reference. Ph.D. dissertation, University of Massachusetts, Amherst. 1985. The syntax of switch-reference. Linguistic Inquiry 16:35-55.

Foley, William A., ANd Robert D. Van Valin, Jr. 1984. Functional Syntax and Universal Grammar. Cambridge: Cambridge University Press.

Givón, T. 2011. Ute Reference Grammar. Amsterdam: John Benjamins.

GORDON, LyNn. 1983. Switch-reference, clause order, and interclausal relationships in Maricopa. Switch-Reference in Universal Grammar, ed. John Haiman and Pamela Munro, pp. 83-104. Amsterdam: John Benjamins.

GRACZYK, RANDOLPH. 2007. A Grammar of Crow. Lincoln: University of Nebraska Press.

Haiman, John, and Pamela Munro, eds. 1983. Switch-Reference and Universal Grammar. Amsterdam: John Benjamins.

Hale, Ken. 1983. Papago (k)c. IJAL 49:299-327. . 1992. Subject obviation, switch-reference, and control. Control and Grammar, ed. Richard K. Larson et al., pp. 51-77. Dordrecht: Kluwer.

Hill, JANE H. 2001. A Grammar of Cupeño. UCPL 136. Berkeley: University of California Press.

HoIJER, HARRY. 1949. Tonkawa syntactic suffixes and anaphoric particles. Southwestern Journal of Anthropology 5:37-55.

ICHIHASHI-NAKAYAMA, KumiKo. 2004. Grammaticization of 'to' and 'away': A unified account of $-k$ and $-m$ in Hualapai. Cognitive and Communicative Approaches to Linguistic Analysis, ed. Ellen Contini-Morava, Robert S. Kirsner, and Bets Rodríguez-Bachiller, pp. 261-73. Amsterdam: John Benjamins.

JaCobSen, William H., JR. 1967. Switch-reference in Hokan-Coahuiltecan. Studies in Southwestern Linguistics, ed. Dell Hymes and William Bittle, pp. 238-63. The Hague: Mouton.

. 1983. Typological and genetic notes on switch-reference in North American languages. Switch-Reference in Universal Grammar, ed. John Haiman and Pamela Munro, pp. 151-83. Amsterdam: John Benjamins.

Keine, Stefan. 2013. Decomposing switch-reference. Natural Language and Linguistic Theory 31:767-826.

Kendall, Martha B. 1976. Selected Problems in Yavapai Syntax. New York: Garland.

Kroeber, Alfred L. 1911. The languages of the coast of California north of San Francisco. University of California Papers on Archaeology, Anthropology, and Ethnology 9:273-435.

Langdon, Margaret. 1970. A Grammar of Diegueño, the Mesa Grande Dialect. UCPL 66. Berkeley: University of California Press.

Langdon, Margaret, and Pamela Munro. 1979. Subject and switch-reference in Yuman. Folia Linguistica 13:321-44. 
Legate, Julie. 2002. Warlpiri: Theoretical implications. Ph.D. dissertation, Massachusetts Institute of Technology.

LungSTRum, Richard. 1995. Switch-reference and the structure of Lakhota narrative discourse. Ph.D. dissertation, University of Pennsylvania.

Marlett, Stephen A. 2013. A not-so-short grammar of Seri. <http://www.und.nodak.edu/ instruct/smarlett/Stephen_Marlett/GrammarDraft.html>.

MARTIN, JACK. 2011. A Grammar of Creek (Muskogee). Lincoln: University of Nebraska Press.

McKenZIE, ANDrew. 2011. Subject domain restriction and reference-tracking. Proceedings of Semantics and Linguistic Theory (SALT) 20, ed. Nan Li and David Lutz, pp. 269-88. Vancouver. . 2012. The role of contextual restriction in reference-tracking. Ph.D. dissertation, University of Massachusetts, Amherst.

Miller, Amy. 2001. A Grammar of Jamul Tiipay. The Hague: Mouton de Gruyter.

Mithun, Marianne. 1993. Switch-reference: Clause combining in Central Pomo. IJAL 59:119-36.

Mixco, Maurício. 1997. Mandan switch reference: A preliminary view. Anthropological Linguistics 39:220-98.

Muenlbauer, JefFrey. 2012. The relation of switch-reference, animacy, and obviation in Plains Cree. IJAL 78:203-38.

Munn, Alan. 1993. Topics in the syntax and semantics of coordinate structures. Ph.D. dissertation, University of Maryland, College Park.

Munro, Pamela. 1983. When 'same' is not 'not different'. Switch-Reference in Universal Grammar, ed. John Haiman and Pamela Munro, pp. 223-43. Amsterdam: John Benjamins.

2005. Chickasaw. Native Languages of the Southeastern United States, ed. Heather K. Hardy and Janine Scancarelli, pp. 114-56. Lincoln: University of Nebraska Press.

Newman, Stanley. 1944. Yokuts Language of California. Viking Fund Publications in Anthropology, no. 2. New York: Viking Fund.

O'Connor, Mary Catherine. 1993. Disjoint reference and pragmatic inference: Anaphora and switch reference in Northern Pomo. The Role of Theory in Language Description, ed. William A. Foley, pp. 215-42. The Hague: Mouton de Gruyter.

Oswalt, Robert L. 1976. Kashaya Dictionary. Berkeley: University of California Press.

Pittman, Christine M. 2005. Non-canonical switch-reference in Inuktitut. Proceedings of the 2005 Annual Conference of the Canadian Linguistic Association, ed. Claire Gurski, pp. 1-12. Montreal.

PRINCE, ElLEN. 1998. The borrowing of meaning as a cause of internal syntactic change. Historical Linguistics 1997: Current Issues in Linguistic Theory, ed. M. Schmid, J. R. Austin, and D. Stein, pp. 339-62. Amsterdam: John Benjamins.

RigGs, Stephen R. 1893/2004. Dakota Grammar with Texts and Ethnography. Minneapolis: Minnesota Historical Society Press.

Rising, DAvid P. 1992. Koasati Switch-Reference in Discourse. Dallas: Summer Institute of Linguistics.

RoBerTs, John. 1988. Amele switch-reference and the theory of grammar. Linguistic Inquiry 19:45-63.

. 1997. Switch-reference in Papua New Guinea. Papers in Papuan Linguistics, ed. Andrew Pauley, vol. 3, pp. 101-241. Canberra: Australian National University.

SAPIR, EdwARD. 1930. Southern Paiute, A Shoshonean Language. Proceedings of the American Academy of Arts and Sciences, vol. 65. Boston: American Academy of Arts and Sciences.

StiRling, Lesley. 1993. Switch-Reference and Discourse Representation. Cambridge: Cambridge University Press.

2001. The multifunctionality of anaphoric expressions: A typological perspective. Australian Journal of Linguistics 21:7-24.

Voegelin, Charles F. 1935. Tübatulabal grammar. University of California Publications in American Archaeology and Ethnology 34:55-190. 
Watahomigie, Lucille J.; Jorigine Bender; Philbert Watahomigie, Sr.; And Akira Y. Yamamoto. 2001. Hualapai Reference Grammar. Revised ed. Kyoto: Endangered Languages of the Pacific Rim.

Watkins, Laurel. 1984. A Grammar of Kiowa. Lincoln: University of Nebraska Press. . 1993. The discourse function of Kiowa switch-reference. Yuman Texts, ed. Margaret Langdon, IJAL-NATS Monograph 3:61-67.

Wiesemann, Ursula. 1982. Switch reference in Bantu languages. Journal of West African Languages 12:42-57.

Woodbury, ANTHONy C. 1983. Switch reference, syntactic organization, and rhetorical structure in Central Yup'ik Eskimo. Switch-Reference in Universal Grammar, ed. John Haiman and Pamela Munro, pp. 291-315. Amsterdam: John Benjamins.

Zigmond, Maurice L.; Curtis G. Booth; and Pamela Munro. 1991. Kawaiisu: A Grammar and Dictionary with Texts. Berkeley: University of California Press. 